\title{
Modification of fluid inclusions in quartz by deviatoric stress. II: experimentally induced changes in inclusion volume and composition
}

\author{
Larryn W. Diamond • Alexandre Tarantola • \\ Holger Stünitz
}

Received: 8 February 2010/Accepted: 25 February 2010/Published online: 24 March 2010

(c) Springer-Verlag 2010

\begin{abstract}
Fluid inclusions in quartz are known to modify their densities during shear deformation. Modifications of chemical composition are also suspected. However, such changes have not been experimentally demonstrated, their mechanisms remain unexplained, and no criteria are available to assess whether deformed inclusions preserve information on paleofluid properties. To address these issues, quartz crystals containing natural $\mathrm{CO}_{2}-\mathrm{H}_{2} \mathrm{O}-\mathrm{NaCl}$ fluid inclusions have been experimentally subjected to compressive deviatoric stresses of $90-250 \mathrm{MPa}$ at $700^{\circ} \mathrm{C}$ and $\sim 600 \mathrm{MPa}$ confining pressure. The resulting microcracking of the inclusions leads to expansion by up to $20 \%$, producing low fluid densities that bear no relation to physical conditions outside the sample. Nevertheless, the chemical composition of the precursor inclusions is preserved. With time the microcracks heal and form swarms of tiny satellite inclusions with a wide range of densities, the highest reflecting the value of the maximum principle
\end{abstract}

Communicated by J.L.R. Touret.

Electronic supplementary material The online version of this article (doi:10.1007/s00410-010-0510-6) contains supplementary material, which is available to authorized users.

L. W. Diamond $(\bowtie) \cdot$ A. Tarantola

Rock-Water Interaction Group, Institute of Geological Sciences, University of Bern, Baltzerstrasse 3, 3012 Bern, Switzerland

e-mail: diamond@geo.unibe.ch

H. Stünitz

Department of Geology, University of Tromsø,

Dramsveien 201, 9037 Troms $\varnothing$, Norway

Present Address:

A. Tarantola

UMR-G2R, Université Henri Poincaré,

54506 Vandoeuvre-lès-Nancy Cedex, France stress, $\sigma_{1}$. These new inclusions lose $\mathrm{H}_{2} \mathrm{O}$ via diffusion, thereby passively increasing their salt and gas contents, and triggering plastic deformation of the surrounding quartz via $\mathrm{H}_{2} \mathrm{O}$-weakening. Using microstructural criteria to identify the characteristic types of modified inclusions, both the pre-deformation fluid composition and syn-deformation maximum stress on the host mineral can be derived from microthermometric analysis and thermodynamic modelling.

Keywords Quartz - Crystal-plasticity · Deformation . Fluid inclusions · Diffusion · Isochores - Reequilibration

\section{Introduction}

Much of the success in applying fluid inclusion studies to understand processes in the Earth's Crust has derived from the fact that many minerals, notably quartz, behave as rigid, chemically impermeable hosts over the pressuretemperature range of interest. Thus, parameters such as paleofluid composition $(X)$ and molar volume $\left(V_{\mathrm{m}}\right)$, or density, can be derived by treating the inclusions as isochoric-isoplethic thermodynamic systems.

Nevertheless, numerous cases are known in which natural fluid inclusions have not preserved their original $V_{\mathrm{m}}-X$ properties since entrapment. Several processes may be responsible for such post-entrapment modifications: at high temperature, diffusion through the host mineral may become fast enough to effect mass transport between the inclusion and its surroundings in response to gradients in chemical potential; changes in rock temperature and in the dependent internal pressure of the inclusions may drive chemical reactions between the inclusion and the host mineral; and changes in external stresses may 
irreversibly modify inclusion volumes. Extraction of useful information from such inclusions relies on criteria to recognize post-entrapment modifications a posteriori and on methods to reconstruct by calculation the net exchanges of chemical constituents and the changes in molar volume. Among the experimentally investigated modifications of fluid inclusions in quartz are the diffusive loss or gain of $\mathrm{H}_{2}$ and $\mathrm{H}_{2} \mathrm{O}$ (e.g. Morgan et al. 1993; Mavrogenes and Bodnar 1994; Hall and Sterner 1995; Bakker and Jansen 1991, 1994; Sterner et al. 1995). These results have been applied to studies of natural samples (e.g. Ridley and Hagemann 1999). Plastic deformation of the host crystal is also known to affect the $V_{\mathrm{m}}-X$ properties of fluid inclusions (Sterner and Bodnar 1989; Vityk et al. 2000; Schmidt et al. 2003). For example, homogenization temperatures, which are dependent on both composition and molar volume, typically become spread over a wide range according to the state of intracrystalline deformation. Küster and Stöckhert (1997) argue that rates of plastic strain as low as $10^{-15} \mathrm{~s}^{-1}$ may cause fluid inclusions to adapt their volumes to the ambient stress regime. It has been postulated that crystal-plastic deformation of quartz drives preferential loss of $\mathrm{H}_{2} \mathrm{O}$ from homogeneous $\mathrm{H}_{2} \mathrm{O}-\mathrm{CO}_{2}$ fluid inclusions, thereby generating the pure $\mathrm{CO}_{2}$ fluid inclusions found in high-grade metamorphic rocks (Hollister 1988, 1990; Bakker and Jansen 1990; Lamb and Moecher 1992; Johnson and Hollister 1995) and in ore deposits hosted by shear-zones (e.g. Schwartz et al. 1992; Klemd et al. 1997; Schmidt Mumm et al. 1997).

To understand the effects of crystal-plastic deformation on fluid inclusion properties, we have subjected natural, fluid-inclusion-bearing quartz crystals to uniaxial compressive (deviatoric) stresses at $700^{\circ} \mathrm{C}$ and $\sim 600 \mathrm{MPa}$. Under these conditions quartz deforms by crystal plasticity. In a companion paper (Tarantola et al. 2010), the resulting modifications of inclusion shapes and microstructures are reported and interpreted. In the present paper, the focus is on modifications of inclusion composition and molar volume (density).

This article first presents the microthermometric and Raman spectroscopic characteristics of the selected fluid inclusions prior to the experiments. The thermodynamic model that is subsequently used to assess the $V_{\mathrm{m}}-X$ modifications is explained. The observed changes in microthermometric and Raman spectroscopic properties after the experiments are then compared to the original values to quantify the modifications. A discussion of the collective microstructural, compositional and volumetric evidence sheds light on the possible mechanisms of the modifications. These in turn suggest criteria by which natural fluid inclusions in plastically deformed quartz can be interpreted.

\section{Methods}

Piston-cylinder experiments

Inclusion-bearing quartz samples were placed in a solid medium, Griggs-type piston-cylinder apparatus and held at $700^{\circ} \mathrm{C}$. Several preparatory experiments were run under hydrostatic confining pressure at $\sim 600 \mathrm{MPa}$ (Hyd-5 and Hyd-6, Fig. 1) and at $\sim 800 \mathrm{MPa}$ (Hyd-4, Fig. 1). Six deformation experiments were performed by compressing the samples uniaxially with a constant load for periods of $12-136 \mathrm{~h}$. The four of these experiments that were buffered with respect to $\mathrm{H}_{2}$ fugacity (Def-1, Def-2, Def-3 and Def-6, Fig. 1) are treated in this article. Details of the experimental method are given in the companion paper (Tarantola et al. 2010).

Fluid inclusions

Quartz plates for the experiments were cut from single, euhedral, freely grown crystals from hydrothermal veins

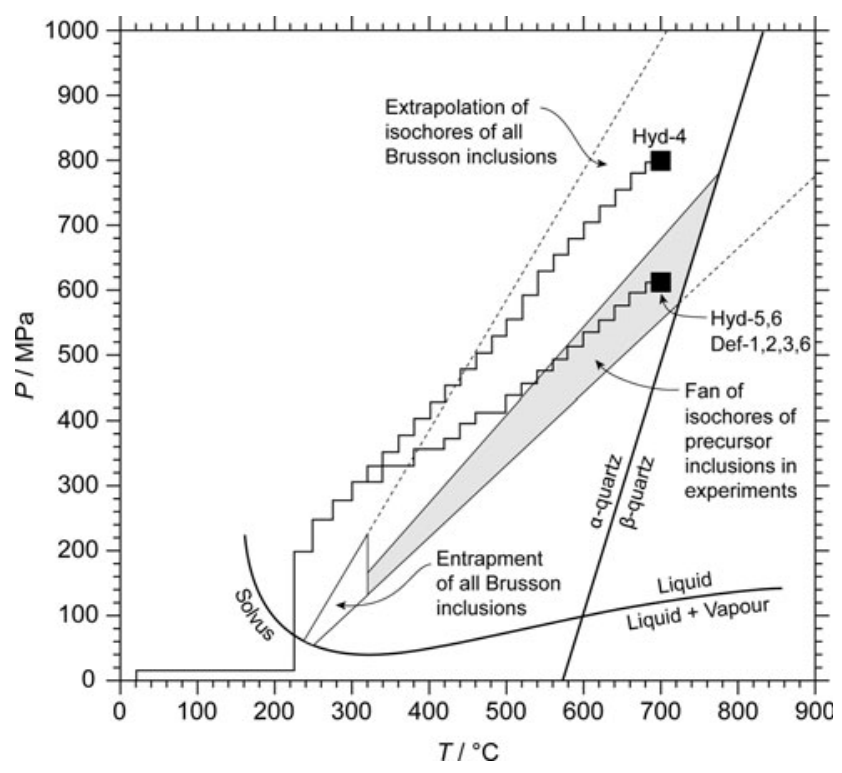

Fig. $1 P-T$ conditions of hydrostatic experiments (squares labelled Hyd-) and deformation experiments involving deviatoric stresses (square labelled Def-). Stepped paths show compression-heating and decompression-cooling trajectories of experiments. Fan of isochores delineating entrapment conditions of all inclusions from Brusson sample locality is taken from Diamond (1990). Extrapolation of fan yields hypothetical internal pressures of all inclusions at $700^{\circ} \mathrm{C}$. Shaded fan of isochores represents subset of inclusions used as "precursors" in experiments. Inclusions in experiment Hyd-4 (800 MPa) experienced negative differential pressure $\left(P_{\text {inc }} \ll P_{\text {conf }}\right)$. Inclusions in Hyd-5,6 and Def-1,2,3,6 (600 MPa) experienced negligible differential pressure $\left(P_{\text {inc }} \approx P_{\text {conf }}\right)$. Quartz phase boundary from Hosieni et al. (1985). Approximate position of fluid solvus interpolated from data in Gehrig (1980) and Krüger and Diamond (2001) 
at the Fenilia gold mine, Brusson, NW Italian Alps, as described by Diamond (1990; sample LD888). All the inclusions used in the experiments were originally trapped from a homogeneous (1 phase) fluid. Although crystals from the same veins also contain heterogeneously trapped inclusions, namely $\mathrm{CO}_{2}$-rich "vapour" inclusions coexisting with immiscible $\mathrm{CO}_{2}$-poor "liquid" inclusions (Diamond 1990), these were purposefully excluded from the present experiments. This point is important, as changes in the volume fractions of inclusion phases are induced during the experiments. Any confusion with originally gas-rich inclusions must therefore be avoided.

At room temperature, the inclusions consist of three fluid phases: a weakly saline aqueous liquid containing 4.0-5.5 mass\% salts (dominantly $\mathrm{NaCl}$ ) and a bubble of carbonic liquid enclosing a bubble of carbonic vapour. The carbonic phases are dominated by $\mathrm{CO}_{2}$ with minor $\mathrm{N}_{2}$ (3$4 \mathrm{~mol} \%)$ and trace $\mathrm{CH}_{4}(<0.07 \mathrm{~mol} \%)$. Some inclusions contain accidentally captured crystallites of muscovite or dolomite. The bulk composition is $90.4-92.2 \mathrm{~mol} \% \mathrm{H}_{2} \mathrm{O}$ and 6.4-4.6 mol\% $\mathrm{CO}_{2}$, the remainder being chloride salts and minor gases. The quartz crystals were formed in open cavities at temperatures between 225 and $300^{\circ} \mathrm{C}$. Further details are given by Diamond (1990).

\section{Characterization of fluid inclusions prior to experiments}

Between 50 and 720 fluid inclusions were selected per sample to represent a range in shape, size and distance to the sample surface. The inclusions were numbered and individually photographed and their positions were mapped to permit relocation after the experiments. Two characteristic phase transitions were measured by microthermometry in 12-84 fluid inclusions in each sample before the experiments. The temperature of clathratehydrate dissociation, $T_{\mathrm{m}}$ (cla), was measured as a monitor of salinity (Diamond 1994). Values lie between 7.5 and $8.5^{\circ} \mathrm{C}$ and dissociation always occurs in the presence of the so-called $\mathrm{Q}_{2}$ phase assemblage: clathrate + aqueous liquid $\left(\mathrm{L}_{\mathrm{aq}}\right)+$ carbonic liquid $\left(\mathrm{L}_{\mathrm{car}}\right)+$ carbonic vapour $\left(\mathrm{V}_{\text {car }}\right)$. The temperature of homogenization of the carbonic phases, $T_{\mathrm{h}}$ (car), was measured as a monitor of bulk density (Diamond 2003). Homogenization occurs between 25.1 and $28.5^{\circ} \mathrm{C}$ via all three possible modes: bubble-point transitions $\left(\mathrm{L}_{\mathrm{aq}} \mathrm{L}_{\mathrm{car}} \mathrm{V}_{\mathrm{car}} \rightarrow \mathrm{L}_{\mathrm{aq}} \mathrm{L}_{\text {car }}\right)$, critical transitions $\left(\mathrm{L}_{\mathrm{aq}} \mathrm{L}_{\mathrm{car}} \mathrm{V}_{\mathrm{car}} \rightarrow \mathrm{L}_{\mathrm{aq}} \mathrm{SCF}_{\mathrm{car}}\right.$, where SCF denotes supercritical fluid) and dew-point transitions $\left(\mathrm{L}_{\mathrm{aq}} \mathrm{L}_{\mathrm{car}}\right.$ $\mathrm{V}_{\mathrm{car}} \rightarrow \mathrm{L}_{\mathrm{aq}} \mathrm{V}_{\text {car }}$ ). For convenience in the presentation of the experimental results, the temperatures of these three transitions are denoted $T_{\text {bub }}(\mathrm{car}), T_{\text {crit }}(\mathrm{car})$ and $T_{\text {dew }}(\mathrm{car})$, respectively. According to the specific inclusion generation, the critical point of the carbonic mixture lies between 28.1 and $28.5^{\circ} \mathrm{C}$. To avoid any deformation or leakage of the inclusions prior to the experiments, the samples were held below $35^{\circ} \mathrm{C}$. Therefore, the total homogenization temperatures, known from Diamond (1990) to lie in the range $225-270^{\circ} \mathrm{C}$, were not measured.

Microthermometry and Raman microspectroscopy were carried out in the Fluid Inclusion Laboratory of the Institute of Geological Sciences, University of Bern. A Linkam $^{\mathrm{TM}}$ THMSG heating-cooling stage was employed, and calibrated using the following phase transitions in synthetic fluid inclusions in quartz: the triple point of $\mathrm{CO}_{2}$ at $-56.6^{\circ} \mathrm{C}$, the triple point of $\mathrm{H}_{2} \mathrm{O}$ at $0.0^{\circ} \mathrm{C}$ and the critical point of $\mathrm{H}_{2} \mathrm{O}$ at $374^{\circ} \mathrm{C}$. The stage was mounted on an Olympus ${ }^{\mathrm{TM}}$ BX51 microscope equipped with $40 \times$ and $100 \times$ long-working distance objectives. Particular attention was paid to the precision to which phase transitions could be measured before and after the experiments. Measurements were initially made on inclusions within the $\sim 2-\mathrm{mm}$ thick plates. After the experiments, most of the plates were polished down to as little as $150 \mu \mathrm{m}$ thickness to remove the superficial extension fractures and thereby enhance visibility of the target inclusions.

The Linkam ${ }^{\mathrm{TM}}$ microthermometry stage operates by vertical heat conduction and the thermocouple is embedded in the heating block. Therefore, samples of different thickness may potentially experience different thermal gradients and hence display different apparent temperatures of phase transitions. To minimize this effect, phase transitions were measured at a heating rate of $2^{\circ} \mathrm{C} \mathrm{min}^{-1}$, and for measurements of $T_{\mathrm{m}}$ (cla) a pause of 20-30 s was made before cooling steps during cycling (Diamond 1992). The overall uncertainties in microthermometry were quantified by measuring 28 fluid inclusions in a standard sample of $2.10 \mathrm{~mm}$ thickness. The sample was then thinned to $1.00 \mathrm{~mm}$, and the remaining 27 inclusions were measured again. Finally, the sample was thinned further to $0.25 \mathrm{~mm}$ and the surviving 16 inclusions measured a third time. Figure 2 illustrates that, despite the variation in sample thickness, the $T_{\mathrm{h}}(\mathrm{car})$ measurements are reproducible to within $\pm 0.1^{\circ} \mathrm{C}$ and the $T_{\mathrm{m}}$ (cla) measurements to within $\pm 0.2^{\circ} \mathrm{C}$. In view of this excellent reproducibility, no additional corrections were applied to the microthermometric data.

The carbonic phases of individual inclusions were analysed for $\mathrm{H}_{2}, \mathrm{~N}_{2}, \mathrm{CH}_{4}$ and $\mathrm{CO}_{2}$ at a few degrees above $T_{\mathrm{h}}$ (car) using a Jobin-Yvon ${ }^{\mathrm{TM}}$ LabRAM HR800 laserRaman spectrometer. Spindle-stage measurements using the method of Bakker and Diamond (2006) showed that the volume fraction of the carbonic phase, $\varphi(\mathrm{car})$, lies within the narrow range $0.18-0.21$ at $T_{\mathrm{h}}(\mathrm{car})$. An example of the measurements is given in "Appendix 1". 
Fig. 2 Reproducibility of microthermometric measurements of $T_{\mathrm{h}}$ (car) and $T_{\mathrm{m}}$ (cla) as a function of thickness of quartz sample. Data from 28 inclusions measured in a plate $2.10 \mathrm{~mm}$ thick ( $x$-axis) are compared to data from the same inclusions measured after thinning the plate successively to 1.00 and $0.25 \mathrm{~mm}$ ( $y$-axis)

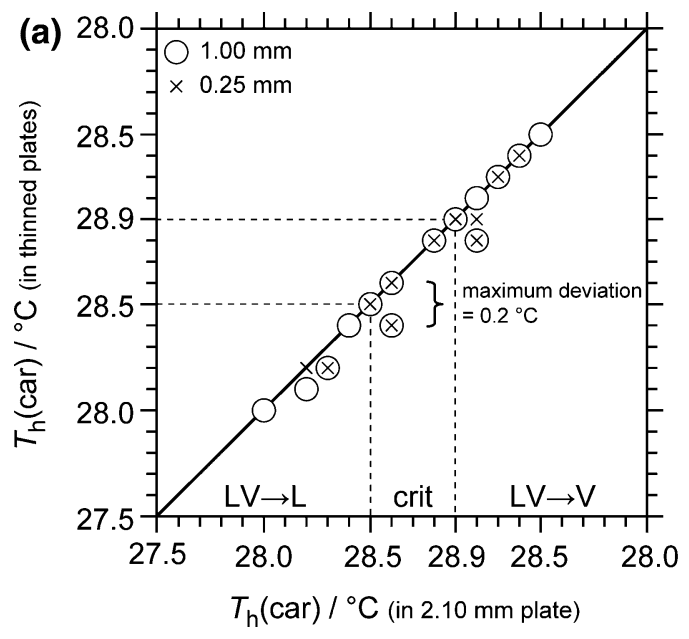

(b)

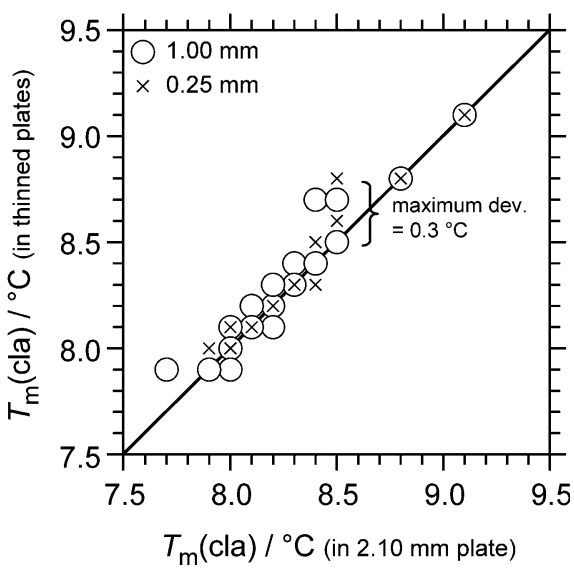

Theoretical basis to monitor changes in inclusion density and composition

\section{Thermodynamic model}

An appropriate thermodynamic model is required to calculate the bulk molar volume (density) and composition of the inclusions from the various measurable parameters. As the 4 species $\mathrm{N}_{2}, \mathrm{CO}_{2}, \mathrm{H}_{2} \mathrm{O}$ and $\mathrm{NaCl}$ account for more than $99.8 \mathrm{~mol} \%$ of the inclusions chosen for the experiments (Table 4 in Diamond 1990), the low- $T$ behaviour of the inclusions can be confidently modelled within the $\mathrm{N}_{2}-$ $\mathrm{CO}_{2}-\mathrm{H}_{2} \mathrm{O}-\mathrm{NaCl}$ system. Estimation of the bulk $V_{\mathrm{m}}-X$ properties thus requires a minimum input of 4 measured parameters. Here, we follow the approach of Diamond (1990, 2003), using $T_{\mathrm{m}}$ (cla) and $T_{\mathrm{h}}$ (car) obtained by microthermometry, $\varphi\left(\right.$ car) estimated optically at $T_{\mathrm{h}}$ (car), and the molar ratio of $\mathrm{N}_{2} / \mathrm{CO}_{2}$ determined by Raman spectroscopy. It turns out that the first three parameters undergo changes during the experiments, whereas in the hematitebuffered experiments the $\mathrm{N}_{2} / \mathrm{CO}_{2}$ ratio remains constant.

Figure 3a shows the relevant phase diagram constructed according to the method of Diamond (1994). The mean observed critical temperature of the carbonic mixture is $28.4^{\circ} \mathrm{C}$. According to the EoS of Peng and Robinson (1976), this temperature implies that the homogenized carbonic phases consist of $96.2 \mathrm{~mol} \% \mathrm{CO}_{2}$ and $3.8 \mathrm{~mol} \%$ $\mathrm{N}_{2}$, a composition which agrees well with the actual Raman analyses. Figure $3 \mathrm{a}$ includes the corresponding $\mathrm{L}_{\mathrm{aq}} \mathrm{L}_{c a r} \mathrm{~V}_{\text {car }}$ envelope, bounded by the dew- and bubble curves and projected from excess $\mathrm{L}_{\mathrm{aq}}$. The amount of aqueous phase in the inclusions can thus vary without influencing the $P-T$ locus of the envelope.

The thin curves traversing the envelope are isochores (calculated with the Peng-Robinson EoS) that span the observed range of densities of the carbonic phases following the experiments (see "Results"). The shaded band of isochores encompasses the observed variation in carbonic phase densities prior to the experiments. To illustrate how changes in molar volume of the carbonic phase, $V_{\mathrm{m}}(\mathrm{car})$, are reflected by changes in $T_{\mathrm{h}}$ (car), consider an inclusion that originally homogenizes at $28.4^{\circ} \mathrm{C}$ at the critical point (point 5 , Fig. 3a), at which $V_{\mathrm{m}}$ (car) $=102 \mathrm{~cm}^{3} \mathrm{~mol}^{-1}$. Any experimentally induced reduction in the molar volume of the carbonic phase will depress $T_{\mathrm{h}}$ (car), such that homogenization occurs via a bubble-point transition. For example, reduction of $V_{\mathrm{m}}$ (car) to $57.2 \mathrm{~cm}^{3} \mathrm{~mol}^{-1}$ leads to homogenization of the carbonic phases at point 1 , where $T_{\text {bub }}($ car $)=12^{\circ} \mathrm{C}$. It is important to appreciate that any experimentally induced increase in $V_{\mathrm{m}}$ (car) will also depress $T_{\mathrm{h}}$ (car), but in this case the carbonic phases will homogenize via a dew-point transition. For example, an increase in $V_{\mathrm{m}}$ (car) to $172.3 \mathrm{~cm}^{3} \mathrm{~mol}^{-1}$ leads to homogenization at point 7 , where $T_{\text {dew }}(\mathrm{car})=24^{\circ} \mathrm{C}$. To aid display of the microthermometric measurements of $T_{\mathrm{h}}$ (car) in the "Results", the hoop-shaped $\mathrm{L}_{\mathrm{aq}} \mathrm{L}_{\mathrm{car}} \mathrm{V}_{\text {car }}$ envelope, consisting of the bubble curve, critical point and dew curve, is straightened out to serve as a one-dimensional axis, as shown along the $x$-axis of Fig. 3b. Although the direction of increasing temperature switches along this axis, it has the advantage of correlating directly with a monotonic increase in molar volume of the carbonic phase.

Also shown in Fig. 3a is the steep dissociation curve of the $\mathrm{N}_{2}-\mathrm{CO}_{2}$ clathrate-hydrate solid-solution, which is in equilibrium with the stipulated composition of the carbonic phase. The curve (labelled $\mathrm{ClaL}_{\mathrm{aq}} \mathrm{L}_{\mathrm{car}}$ at high pressure and labelled " $\mathrm{Q}_{2}$ segment" where it cuts the $\mathrm{L}_{\mathrm{aq}} \mathrm{L}_{\mathrm{car}} \mathrm{V}_{\text {car }}$ envelope) was calculated using the curves code of Bakker (2003) for an aqueous $\mathrm{NaCl}$ concentration of 3.7 mass \%. Progressive increase in aqueous $\mathrm{NaCl}$ concentration drives this curve to lower temperatures. Therefore, the aqueous salinity of the inclusions is calculated from $T_{\mathrm{m}}$ (cla) by incrementing the modelled $\mathrm{NaCl}$ concentration until the temperature at which the inclusion 

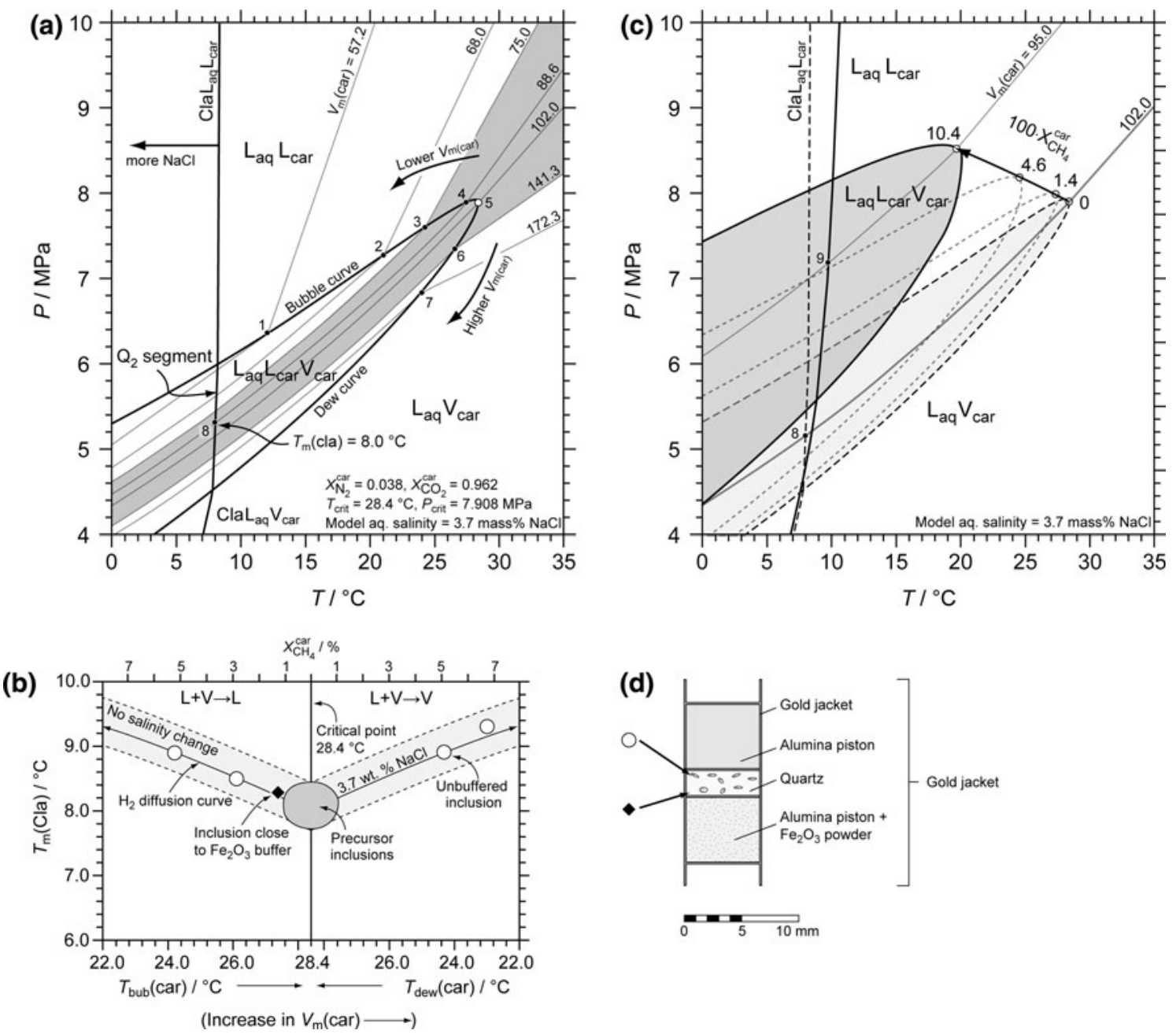

Fig. 3 a Low $P-T$ phase relations of the fluid inclusions used in the experiments, projected from excess aqueous liquid $\left(\mathrm{L}_{\mathrm{aq}}\right)$. Steep curve is upper stability limit of clathrate. Fine lines are isochores. Grey field encompasses observed range of isochores prior to experiments; other isochores represent observed range after experiments. The carbonic phases $\left(\mathrm{L}_{\mathrm{car}}\right.$ and $\left.\mathrm{V}_{\mathrm{car}}\right)$ homogenize on the boundary of the phase envelope made up of the bubble curve, critical point (marked 5), and dew curve. b Effect of addition of $\mathrm{H}_{2}$ on measurable phase transitions. Precursor inclusions that originally homogenized on the bubble curve move to the left along the $\mathrm{H}_{2}$ diffusion curve; inclusions that originally homogenized on the dew curve move to the right. $\mathbf{c}$ Phase

isochore intersects the dissociation curve (e.g. point 8) matches the observed $T_{\mathrm{m}}$ (cla) (e.g. $8.0^{\circ} \mathrm{C}$ ) (Diamond 1994). Any experimentally induced loss of $\mathrm{H}_{2} \mathrm{O}$ from the inclusions will increase the residual salinity and shift $T_{\mathrm{m}}$ (cla) to lower values. Similarly, any addition of $\mathrm{H}_{2} \mathrm{O}$ to the inclusions will shift $T_{\mathrm{m}}$ (cla) to higher values. Figure 3a shows that the $\mathrm{Q}_{2}$ segment of the clathrate dissociation curve is extremely steep. When the precision of $T_{\mathrm{m}}$ (cla) measurements is taken into account $\left( \pm 0.2^{\circ} \mathrm{C}\right)$, the $\mathrm{Q}_{2}$ segment can be treated as essentially vertical (isothermal). This means that any experimentally induced

changes in $V_{\mathrm{m}}$ (car) will not affect $T_{\mathrm{m}}$ (cla). Shifts in $T_{\mathrm{m}}$ (cla) therefore serve as a strict monitor of changes in aqueous salinity. Thus, values of $T_{\mathrm{m}}$ (cla) can be recast in terms of aqueous $\mathrm{NaCl}$ concentration to serve as a parallel axis in the plots of microthermometric data (e.g. $y$-axis in Fig. 3b).

The bulk $V_{\mathrm{m}}-X$ properties of the inclusions may be calculated by first extracting the following 3 parameters from the above phase diagram: the pressure inside the inclusions at $T_{\mathrm{h}}$ (car), denoted $P_{\mathrm{h}}(\mathrm{car})$; the molar volume of the carbonic phases, $V_{\mathrm{m}}(\mathrm{car})$ at $T_{\mathrm{h}}(\mathrm{car})$; and the mole 
fractions of $\mathrm{H}_{2} \mathrm{O}$ and $\mathrm{NaCl}$ in the $\mathrm{H}_{2} \mathrm{O}-\mathrm{NaCl}$ binary subsystem (here termed "brine"), $X_{\mathrm{H}_{2} \mathrm{O}}^{\text {brine }}$ and $X_{\mathrm{NaCl}}^{\text {brine }}$. The mole fractions of $\mathrm{N}_{2}$ and $\mathrm{CO}_{2}$ in the carbonic phase at $T_{\mathrm{h}}$ (car), $X_{\mathrm{N}_{2}}^{\mathrm{car}}$ and $X_{\mathrm{CO}_{2}}^{\mathrm{car}}$, are directly known from Raman analysis. The concentrations of $\mathrm{N}_{2}$ in the aqueous phase and of $\mathrm{H}_{2} \mathrm{O}$ in the carbonic phase can be neglected under these conditions (Akinfiev and Diamond 2003). In contrast, the concentration of $\mathrm{CO}_{2}$ in the aqueous phase, $X_{\mathrm{CO}_{2}}^{\mathrm{aq}}$, is significant and is obtained from the EoS by Akinfiev and Diamond (submitted) along with the molar volume of the aqueous phase, $V_{\mathrm{m}}(\mathrm{aq})$, now treated as a $\mathrm{CO}_{2}-\mathrm{H}_{2} \mathrm{O}-\mathrm{NaCl}$ ternary. All these parameters are inserted into the following set of volume- and mass-balance equations (Diamond 2001). Thus, the bulk molar volume, $V_{\mathrm{m}}(\mathrm{tot})$, is given by:

$V_{\mathrm{m}}(\mathrm{tot})=\frac{V_{\mathrm{m}}(\mathrm{aq}) \cdot V_{\mathrm{m}}(\mathrm{car})}{V_{\mathrm{m}}(\mathrm{car})+\varphi(\mathrm{car})\left(V_{\mathrm{m}}(\mathrm{aq})-V_{\mathrm{m}}(\mathrm{car})\right)}$

The mole fraction of the homogeneous carbonic phase is found from the relation:

$X_{\mathrm{car}}^{\mathrm{tot}}=\frac{V_{\mathrm{m}}(\mathrm{tot}) \cdot V_{\mathrm{m}}(\mathrm{aq})}{V_{\mathrm{m}}(\mathrm{car}) \cdot V_{\mathrm{m}}(\mathrm{aq})}$,

which allows calculation of the bulk composition in terms of the 4 selected components:

$X_{\mathrm{N}_{2}}^{\mathrm{tot}}=X_{\mathrm{car}}^{\mathrm{tot}} \cdot X_{\mathrm{N}_{2}}^{\mathrm{car}}$

$X_{\mathrm{CO}_{2}}^{\mathrm{tot}}=X_{\mathrm{car}}^{\mathrm{tot}} \cdot X_{\mathrm{CO}_{2}}^{\mathrm{car}}+\left(1-X_{\mathrm{car}}^{\mathrm{tot}}\right) X_{\mathrm{CO}_{2}}^{\mathrm{aq}}$,

$X_{\mathrm{H}_{2} \mathrm{O}}^{\mathrm{tot}}=\left(1-X_{\mathrm{car}}^{\mathrm{tot}}\right) X_{\mathrm{H}_{2} \mathrm{O}}^{\mathrm{aq}}$,

$X_{\mathrm{NaCl}}^{\mathrm{tot}}=\left(1-X_{\mathrm{car}}^{\mathrm{tot}}\right) X_{\mathrm{NaCl}}^{\mathrm{aq}}$.

Thermodynamic model of $\mathrm{H}_{2}$ gains

After analysing a first set of experiments, it was realized that hydrogen diffuses from the piston-cylinder assembly through the quartz into the inclusions, where it reacts with $\mathrm{CO}_{2}$ as follows (e.g. Morgan et al. 1993):

$4 \mathrm{H}_{2}+\mathrm{CO}_{2} \rightarrow \mathrm{CH}_{4}+2 \mathrm{H}_{2} \mathrm{O}$.

Therefore, in subsequent experiments $\mathrm{Fe}_{2} \mathrm{O}_{3}$ powder was added to the sample capsules to buffer $f\left(\mathrm{H}_{2}\right)$ at a negligible level:

$3 \mathrm{Fe}_{2} \mathrm{O}_{3(\mathrm{~s})}+\mathrm{H}_{2(\mathrm{~g})} \rightarrow 2 \mathrm{Fe}_{3} \mathrm{O}_{4(\mathrm{~s})}+\mathrm{H}_{2} \mathrm{O}_{(\mathrm{l})}$.

For the unbuffered experiments, it is still possible to interpret the microthermometric results meaningfully by taking account of reaction (7) in the thermodynamic model. Thus, the change in gas composition and in $\mathrm{H}_{2} \mathrm{O}$ concentration induced in the fluid inclusions by reaction (7) causes $T_{\mathrm{h}}$ (car) and $T_{\mathrm{m}}$ (cla) to become interdependent. The effect of this reaction on the two phase transitions is modelled in Fig. $3 \mathrm{c}$ using the same approach as mentioned earlier. With the concentrations of $\mathrm{C}, \mathrm{O}, \mathrm{N}_{2}$ and $\mathrm{NaCl}$ held constant, the reaction of $\mathrm{CO}_{2}$ to $\mathrm{CH}_{4}$ decreases $T_{\mathrm{h}}$ (car), while the mode of homogenization remains unchanged. At the same time, the clathrate dissociation curve becomes less steep and it is shifted to distinctly higher temperatures at marginally lower salinity (owing to dilution by the $\mathrm{H}_{2} \mathrm{O}$ produced via reaction (7)). Thus, a decrease in $T_{\mathrm{h}}(\mathrm{car})$ is coupled to an increase in $T_{\mathrm{m}}$ (cla).

Consider, for example, an inclusion initially with no $\mathrm{CH}_{4}$ and with $T_{\mathrm{h}}(\mathrm{car})=28.4^{\circ} \mathrm{C}$ at the critical point labelled 0 in Fig. 3c. Production of $10 \mathrm{~mol} \% \mathrm{CH}_{4}$ in the carbonic phase will depress $T_{\mathrm{h}}$ (car) to $19.7^{\circ} \mathrm{C}$ at the critical point labelled 10.4. This change in gas composition will also shift the clathrate dissociation temperature from $8.0^{\circ} \mathrm{C}$ at point 8 to $9.7^{\circ} \mathrm{C}$ at point 9 .

The quantitative model in Fig. $3 \mathrm{c}$ allows a reference " $\mathrm{H}_{2}$ diffusion curve" to be plotted in Fig. 3b, against which the progress of reaction (7) can be monitored. The curve is calculated for a model inclusion initially with $T_{\text {crit }}(\mathrm{car})=28.4^{\circ} \mathrm{C}$. Because the mode by which the carbonic phases homogenize does not change as $\mathrm{H}_{2}$ is added, inclusions that originally underwent bubble-point transitions will shift to the left in Fig. 3b, parallel to the reference curve. Conversely, inclusions that originally underwent dew-point transitions will shift to the right in Fig. $3 b$ as $\mathrm{H}_{2}$ is added.

\section{Results}

The results of the two series of experiments (hydrostaticand deviatoric-stress) are presented separately below. As the inclusions tend to split apart during the experiments and adopt new microstructures (details in Tarantola et al. 2010), the following nomenclature is used to facilitate their description (Fig. 4): "Intact" inclusions are those that survived as single objects during the experiments, regardless of any changes in shape; "Dismembered" inclusions usually generate a "cluster" of inclusions consisting of a recognizable "relict" of the "precursor" surrounded by

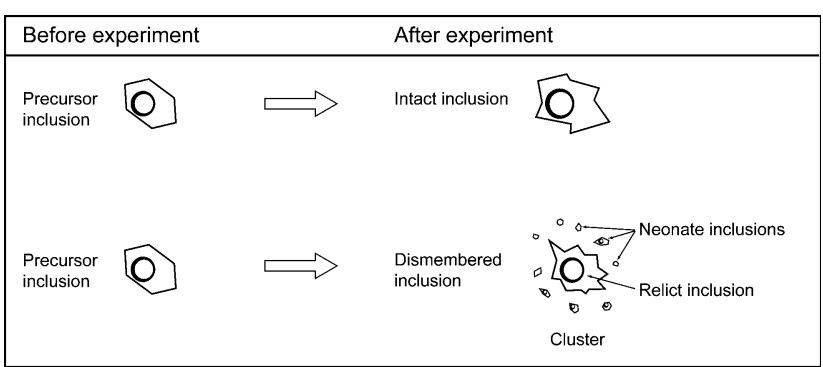

Fig. 4 Nomenclature of fluid inclusions modified by deviatoric stresses 
smaller "neonate" inclusions that formed entirely during the experiments.

In evaluating the microthermometric results, it is important to bear in mind a shortcoming of our experimental method. Although between 12 and 84 inclusions were analysed by microthermometry prior to each experiment, few of these specific inclusions could be measured again after the experiments. In some cases the samples had broken at crucial points, and in others the new shapes acquired by the relict inclusions were so irregular (including narrow tubes and tails) that reliable measurement of $T_{\mathrm{m}}$ (cla) was impossible (Diamond 1992). However, many of the inclusions that had been simply photographed prior to the experiments could be successfully relocated and analysed. Consequently, the microthermometric measurements collected after the experiments largely pertain to different sets of inclusions from those referred to below as the "precursors". This shortcoming reduces the resolution to which changes in $V_{\mathrm{m}}-X$ properties can be ascertained, but it will be seen that the changes are in any case large enough to be defined unequivocally.

\section{Hydrostatic scoping experiments}

Table 1 lists the experimental conditions and key observations pertaining to the hydrostatic experiments. Table 2 shows the microthermometric results.

Experiment Hyd-4 (unbuffered) was conducted at $800 \mathrm{MPa}\left(\Delta P=P_{\text {inc }}-P_{\text {conf }} \sim-200 \mathrm{MPa}\right)$ for $16 \mathrm{~h}$. Phase transition temperatures showed shifts (Fig. 5a; Table 3): $T_{\mathrm{m}}$ (cla) had dropped from an average of $8.1^{\circ} \mathrm{C}$ before to $7.1^{\circ} \mathrm{C}$ after the experiment, and the dew points of the carbonic phases fell from 27.5 to $26.8^{\circ} \mathrm{C}$ before to $25.2-$ $22.8^{\circ} \mathrm{C}$ after the experiment. The carbonic phases were found by Raman to be enriched in $\mathrm{CH}_{4}$ produced via reaction (7) upon influx of $\mathrm{H}_{2}$. While this accounts for the decrease in $T_{\text {dew }}(\mathrm{car})$, it is inconsistent with the observed reduction in $T_{\mathrm{m}}$ (cla), as the inclusions lie far below the $\mathrm{H}_{2^{-}}$ diffusion band in Fig. 5a. It follows that the aqueous salinity of the inclusions had increased during the experiment.

Experiment Hyd-5 (unbuffered) was conducted at $600 \mathrm{MPa}(\Delta P \sim 0)$ for $16 \mathrm{~h}$. Raman analysis showed an increase in the concentration of $\mathrm{CH}_{4}$ in the carbonic phase. The phase transition temperatures are accordingly more scattered (Fig. 5b), but all the inclusions lie within or very close to the model $\mathrm{H}_{2}$-diffusion band, consistent with reaction (7).

Experiment Hyd-6 (buffered by hematite at base, as shown in Fig. 3d) was performed at $600 \mathrm{MPa}(\Delta P \sim 0)$ for $139 \mathrm{~h}$. After the run, the initially reddish-brown buffer powder had turned greenish-black, and Raman analysis showed it to be an intergrowth of hematite and magnetite. The inclusions that were situated near the hematite powder display only slight shifts in phase transition temperatures (diamonds in Fig. 5c) and they contained no new $\mathrm{CH}_{4}$ according to Raman analysis. In contrast, the inclusions near the upper, unbuffered face of the sample (Fig. 3d) acquired abundant $\mathrm{CH}_{4}$ and they plot as expected along the $\mathrm{H}_{2}$ diffusion curve (circles in Fig. 5c). These observations demonstrate the effectiveness of the hematite buffer via reaction (8). However, no trace was found of the $\mathrm{H}_{2} \mathrm{O}$ generated by this reaction, for example in the form of new fluid inclusions within the adjacent quartz.

The aforementioned microthermometric evidence supports the conclusion in Tarantola et al. (2010), based on fluid inclusion shapes and microstructures, that differential hydrostatic pressure on the inclusions in our particular samples is negligible under the conditions of experiment Hyd-6. Only a slight reequilibration of the $\mathrm{H}_{2}$-buffered inclusions is revealed by the shift in $T_{\text {bub }}$ (car) to a mean of $27.4^{\circ} \mathrm{C}$ (compare precursor field with diamonds, Fig. 5c). Accordingly, the subsequent deformation experiments were all performed at $700^{\circ} \mathrm{C}$ with $P_{\text {conf }}=\sigma_{3} \approx 600 \mathrm{MPa}$, under the assumption that this fulfils the condition $\left(P_{\text {inc }}-P_{\text {conf }}\right)=0$.

\section{Uniaxial compression experiments}

The run conditions and microthermometric data for the four hematite-buffered deformation experiments involving deviatoric stress are listed in Tables 3 and 4. The results are presented in the following order of increasing strain: Def-1 (lowest strain), Def-2 (moderate strain) and Def-3 (medium strain). Experiment Def-6 is presented thereafter because its strain could not be determined, owing to sample disintegration. Following the details of each experiment, the volume fractions of the carbonic phases, $\varphi$ (car), and the calculated bulk $V_{\mathrm{m}}-X$ properties are presented for all the experiments simultaneously. The final section describes the fluid inclusions found in vertical mode-I fractures.

Table 1 Experimental conditions and main observations of hydrostatic experiments at $700^{\circ} \mathrm{C}$

\begin{tabular}{llllcl}
\hline Exp. & Basel lab no. & $\mathrm{Fe}_{2} \mathrm{O}_{3}$ buffer & $P(\mathrm{MPa})$ & Duration (hours) & Comments \\
\hline Hyd-4 & $129 \mathrm{AT}$ & No & 800 & 16 & Formation of $\mathrm{CH}_{4}$; irregular-shaped inclusions; 3D-haloes \\
Hyd-5 & $130 \mathrm{AT}$ & No & 600 & 16 & Formation of $\mathrm{CH}_{4}$; euhedral inclusions \\
Hyd-6 & $139 \mathrm{AT}$ & Yes & 600 & 139 & No formation of $\mathrm{CH}_{4}$; euhedral inclusions \\
\hline
\end{tabular}



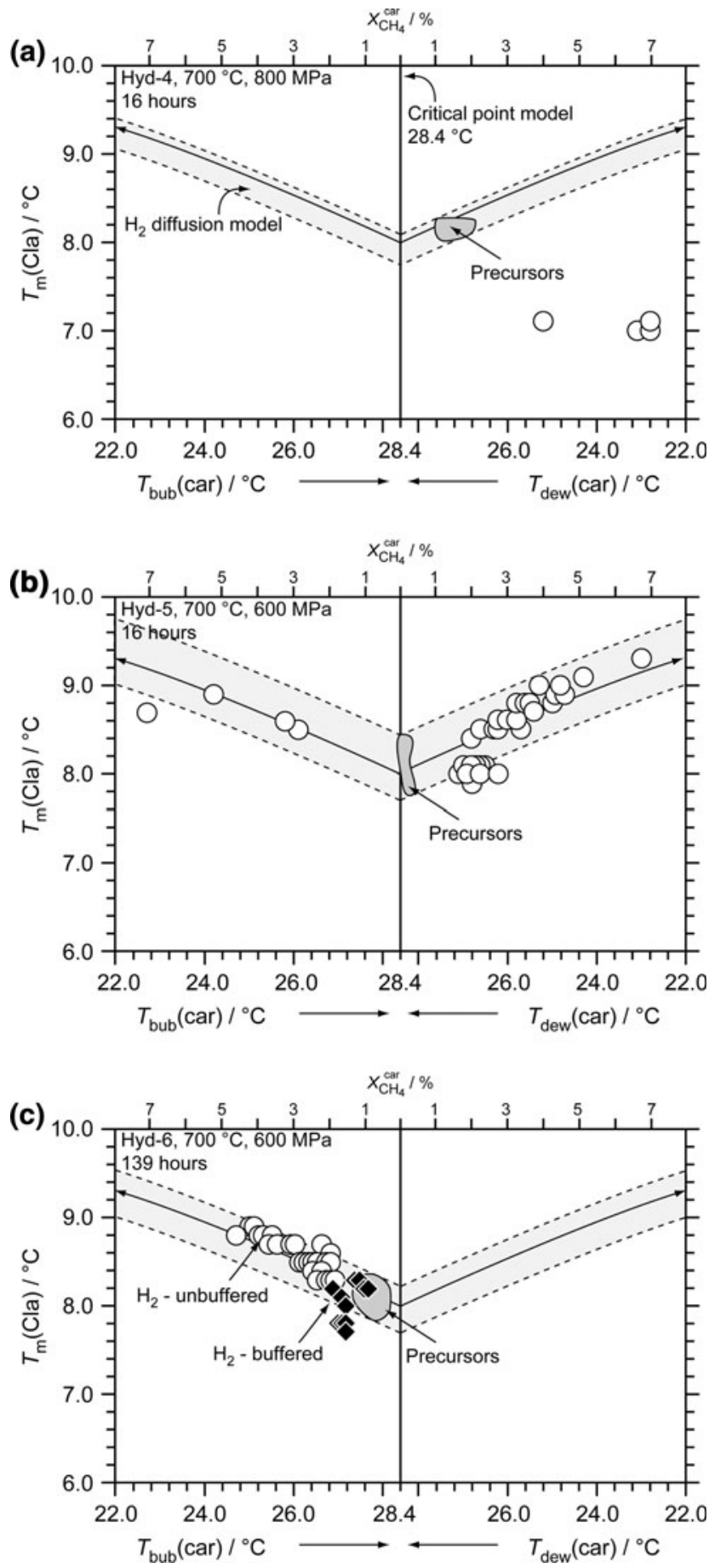

\section{Lowest strain experiment Def-1}

After being subjected to $\Delta \sigma=92 \mathrm{MPa}$ for $110 \mathrm{~h}$, the strain in this quartz sample was very low $(<0.2 \%)$. None of the inclusions changed their gas compositions. The intact inclusions show no significant modifications of their microthermometric properties (triangles in Fig. 6a) versus the precursor inclusions (shaded field in Fig. 6a), despite their changes in shape (Fig. 5 in Tarantola et al. 2010). The
Fig. 5 Microthermometric results, $T_{\mathrm{m}}$ (cla) and $T_{\mathrm{h}}$ (car), for fluid inclusions before and after hydrostatic experiments. Axes are explained in Fig. 3b. Dark-shaded fields denote precursor inclusions. Light-shaded bands show modelled effects of $\mathrm{H}_{2}$ influx for inclusions that contain $\mathrm{CH}_{4}$ according to Raman analysis. a Experiment Hyd-4, conducted at $800 \mathrm{MPa}$ without an $\mathrm{H}_{2}$-buffer. Data (circles) lie far below model $\mathrm{H}_{2}$-diffusion curve, indicating loss of $\mathrm{H}_{2} \mathrm{O}$ from the inclusions in addition to addition of $\mathrm{H}_{2}$. b Experiment Hyd-5, conducted at $600 \mathrm{MPa}$ without an $\mathrm{H}_{2}$-buffer. Most data fall in band indicating influx of $\mathrm{H}_{2}$. Contents of $\mathrm{CH}_{4}$ in carbonic phases are up to $7 \mathrm{~mol} \%$. c Experiment Hyd-6, conducted at $600 \mathrm{MPa}$ with $\mathrm{H}_{2}$ buffer $\left(\mathrm{Fe}_{2} \mathrm{O}_{3}\right.$ powder) situated below sample (setup in Fig. 3d). Data for inclusions near unbuffered top surface of sample (circles) show increases of up to $5 \mathrm{~mol} \% \mathrm{CH}_{4}$ in carbonic phase due to $\mathrm{H}_{2}$ influx, as confirmed by Raman analysis. Inclusions near buffered lower surface of sample showed no $\mathrm{CH}_{4}$ in Raman analysis. Their data (diamonds) show shifts to left of precursors owing to slight decrease in bulk molar volume. This relationship illustrates the effectiveness of the $\mathrm{H}_{2}$ buffer

relicts of dismembered inclusions (circles in Fig. 6a) display somewhat scattered microthermometric values, but no consistent trends in $V_{\mathrm{m}}(\mathrm{car})$ or salinity are visible. In contrast, the neonate inclusions (black squares in Fig. 6a) have significantly lower $V_{\mathrm{m}}$ (car) and higher aqueous salinity, as reflected by the strong shifts to lower $T_{\text {bub }}$ (car) and $T_{\mathrm{m}}$ (cla) values.

\section{Moderate strain experiment Def-2}

After $136 \mathrm{~h}$ with $\Delta \sigma=135 \mathrm{MPa}$, the gas compositions of the intact and relict inclusions were unchanged. Raman analyses of monophase neonates revealed the presence of dissolved $\mathrm{CO}_{2}$ in aqueous solution.

Intact inclusions show no change in $V_{\mathrm{m}}$ (car) but a notable increase in aqueous salinity (Fig. 6b). The microthermometric values of the relict inclusions are quite distinct from those of their satellite neonates. Whereas the relicts now display dew-points at temperatures as low as $24.0^{\circ} \mathrm{C}$, the neonates undergo bubble-point transitions over a broad range, at temperatures down to $18.6^{\circ} \mathrm{C}$, well below those of the precursor inclusions. Clathrate dissociates consistently as part of the $\mathrm{Q}_{2}$ assemblage, as it did prior to the experiment, but at systematically lower temperatures. Relict inclusions show an increase in aqueous salinity of about 1 mass\%, whereas all the neonate inclusions have increased by about 2.5 mass $\%$. As shown by the tie-lines in Fig. $6 \mathrm{~b}$, in any given cluster of dismembered inclusions, the relict always displays higher $V_{\mathrm{m}}$ (car) and lower aqueous salinity than the surrounding neonates (Table 3).

\section{Medium strain experiment Def-3}

After being subjected to $\Delta \sigma=162 \mathrm{MPa}$ for $110 \mathrm{~h}$, most of the inclusions had split into clusters of neonates. Raman microspectroscopy showed that the gas compositions remained unchanged, and that the flat, monophase neonates 
Table 2 Microthermometric data of hydrostatic experiments

\begin{tabular}{|c|c|c|c|c|c|c|c|}
\hline \multirow[t]{2}{*}{ Exp. } & \multirow[t]{2}{*}{ Hom. mode of $\operatorname{car}^{\mathrm{a}}$} & \multicolumn{3}{|c|}{ Before experiment } & \multicolumn{3}{|c|}{ After experiment } \\
\hline & & $N$ & $T_{\mathrm{m}}(\mathrm{cla})^{\mathrm{b}}\left({ }^{\circ} \mathrm{C}\right)$ & $T_{\mathrm{h}}(\mathrm{car})^{\mathrm{c}}\left({ }^{\circ} \mathrm{C}\right)$ & $N$ & $T_{\mathrm{m}}(\mathrm{cla})^{\mathrm{b}}\left({ }^{\circ} \mathrm{C}\right)$ & $T_{\mathrm{h}}(\mathrm{car})^{\mathrm{c}}\left({ }^{\circ} \mathrm{C}\right)$ \\
\hline Hyd-4 & Dew point & 12 & $7.9-8.2(8.1)$ & $26.8-27.5(27.3)$ & 4 & $7.0-7.1(7.1)$ & $22.8-25.2(23.5)$ \\
\hline \multirow[t]{3}{*}{ Hyd-5 } & Bubble point & & & & 5 & $8.5-8.9(8.7)$ & $22.7-26.1(24.6)$ \\
\hline & Critical & & & & 4 & 7.9-8.1 (8.0) & $26.8-27.1(27.0)$ \\
\hline & Dew point & 14 & $7.8-8.4(8.1)$ & $28.1-28.4(28.3)$ & 31 & $8.0-9.3(8.6)$ & $23.0-26.9(25.8)$ \\
\hline Hyd-6 buffered ${ }^{\mathrm{d}}$ & Bubble point & 32 & $7.9-8.3(8.1)$ & $27.4-28.1(28.0)$ & 29 & $7.7-8.3(8.1)$ & 26.9-27.7 (27.4) \\
\hline Hyd-6 no bufferr ${ }^{\mathrm{d}}$ & Bubble point & & & & 39 & $8.3-8.9(8.5)$ & $24.7-26.9(26.1)$ \\
\hline
\end{tabular}

contain $\mathrm{CO}_{2}$ dissolved in the metastable aqueous liquid. Only a few intact inclusions were found and, except for one case in which salinity had increased, the inclusions had undergone no changes in microthermometric values (Fig. 6c; Table 4). Relict and neonate inclusions show the same microthermometric trends as observed in experiment Def-2, but more pronounced. Here again, within each inclusion cluster, with one exception, $V_{\mathrm{m}}$ (car) of the relicts is always higher and aqueous salinity is always lower than in the associated satellite neonates (tie-lines, Fig. 6c). In the relict inclusions, $T_{\mathrm{h}}$ (car) is as low as 25.8 (dew-point) or $24.9^{\circ} \mathrm{C}$ (bubblepoint), and the aqueous salinity shows a wider range than the precursors. Values of $T_{\mathrm{h}}$ (car) in the neonate inclusions scatter over a huge range from 11.9 to $28.1^{\circ} \mathrm{C}$, the phase transition always being a bubble point. Clathrate always dissociates within the $\mathrm{Q}_{2}$ assemblage, revealing a systematic increase in aqueous salinity by about 1 mass $\%$.

\section{Experiment Def-6}

The general trends in microthermometric values after the experiment (Fig. 6d) are comparable to those in Def-1, Def-2 and Def-3. Intact inclusions do not vary from the precursor properties. All the inclusions show $T_{\mathrm{m}}$ (cla) values over a somewhat wider range but still centred on the field of the precursor inclusions. Also the $T_{\mathrm{h}}(\mathrm{car})$ values are more widely scattered: the relict inclusions display both lower bubble-point and dew-point transitions (the latter by as much as $3^{\circ} \mathrm{C}$ below the average precursor), but salinity remains approximately constant. Neonate inclusions define a clear trend towards lower $T_{\text {bub }}$ (car) at constant salinity.

\section{Volume fractions of the carbonic phases, $\varphi($ car)}

In all the deformation experiments, the intact inclusions retained the $\varphi($ car $)$ values of the precursors $(\sim 0.18-0.21)$ as measured at room temperature. The neonate inclusions are difficult to measure with the spindle stage and so in the cases where flat inclusions were found, their area-fractions were measured and taken as directly equivalent to volume fractions. Overall, the values were found to be very similar or slightly lower than the precursors: $\varphi($ car $)=0.15-0.20$. Phase volume fractions were also difficult to measure in the relict inclusions owing to their highly irregular shapes (for which the method of Bakker and Diamond 2006 is not valid). Subjective optical estimates indicate a range of $\varphi$ (car) between 0.20 and 0.35 . The range is not random but rather follows a distinct correlation with $V_{\mathrm{m}}$ (car) values of the relicts. Inclusions with $V_{\mathrm{m}}$ (car) around $80 \mathrm{~cm}^{3} \mathrm{~mol}^{-1}$ (Fig. 6) have $\varphi$ (car) $\sim 0.20$, and as $V_{\mathrm{m}}$ (car) increases to around $170 \mathrm{~cm}^{3} \mathrm{~mol}^{-1}$ the $\varphi($ car) values progressively rise to $\sim 0.35$.

\section{Changes in fluid inclusion bulk $V_{m}-X$ properties}

The foregoing results from the deformation experiments permit the bulk $V_{\mathrm{m}}-X$ properties of the inclusions to be calculated from Eqs. 1 to 6 . Figure 7 illustrates the results for selected inclusions from the four deformation experiments reported in Fig. 6. In general, all four experiments show the same trends: (1) The intact inclusions closely retain the $V_{\mathrm{m}}-X$ values of the precursor inclusions; (2) Most of the relict inclusions preserve the composition of the precursors, except for some examples in Def-2 and Def3 in which $\mathrm{H}_{2} \mathrm{O}$ contents have slightly decreased and the salt and gas contents have increased. Most notable is the wide spread in molar volumes of the relict inclusions, spanning the range from somewhat lower values than the precursors up to much higher volumes; (3) Compared to the precursors, the neonates all display a clear trend towards lower molar volumes, lower $\mathrm{H}_{2} \mathrm{O}$ contents and higher $\mathrm{NaCl}$ and gas contents. The neonates mostly have 
Fig. 6 Microthermometric results, $T_{\mathrm{m}}$ (cla) and $T_{\mathrm{h}}$ (car), for fluid inclusions before and after deformation experiments involving deviatoric stresses $(\Delta \sigma)$. Temperature axis correlates non-linearly with molar volume of carbonic phases, $V_{\mathrm{m}}$ (car), shown in top scale (explained in Fig. 3a). Vertical line at $28.4^{\circ} \mathrm{C}$ denotes critical temperature of carbonic phases in precursor inclusions. Vertical $T_{\mathrm{m}}$ (cla) axis correlates inversely with aqueous salinity (right scale). Shaded field encompasses all data for precursor inclusions.

a Experiment Def-1, conducted with $\Delta \sigma=92 \mathrm{MPa}$ for $110 \mathrm{~h}$.

b Experiment Def-2, conducted with $\Delta \sigma=135 \mathrm{MPa}$ for $136 \mathrm{~h}$. c Experiment Def-3, conducted with $\Delta \sigma=162 \mathrm{MPa}$ for $110 \mathrm{~h}$. d Experiment Def-6, conducted with $\Delta \sigma=217 \mathrm{MPa}$ over short duration, $17 \mathrm{~h}$
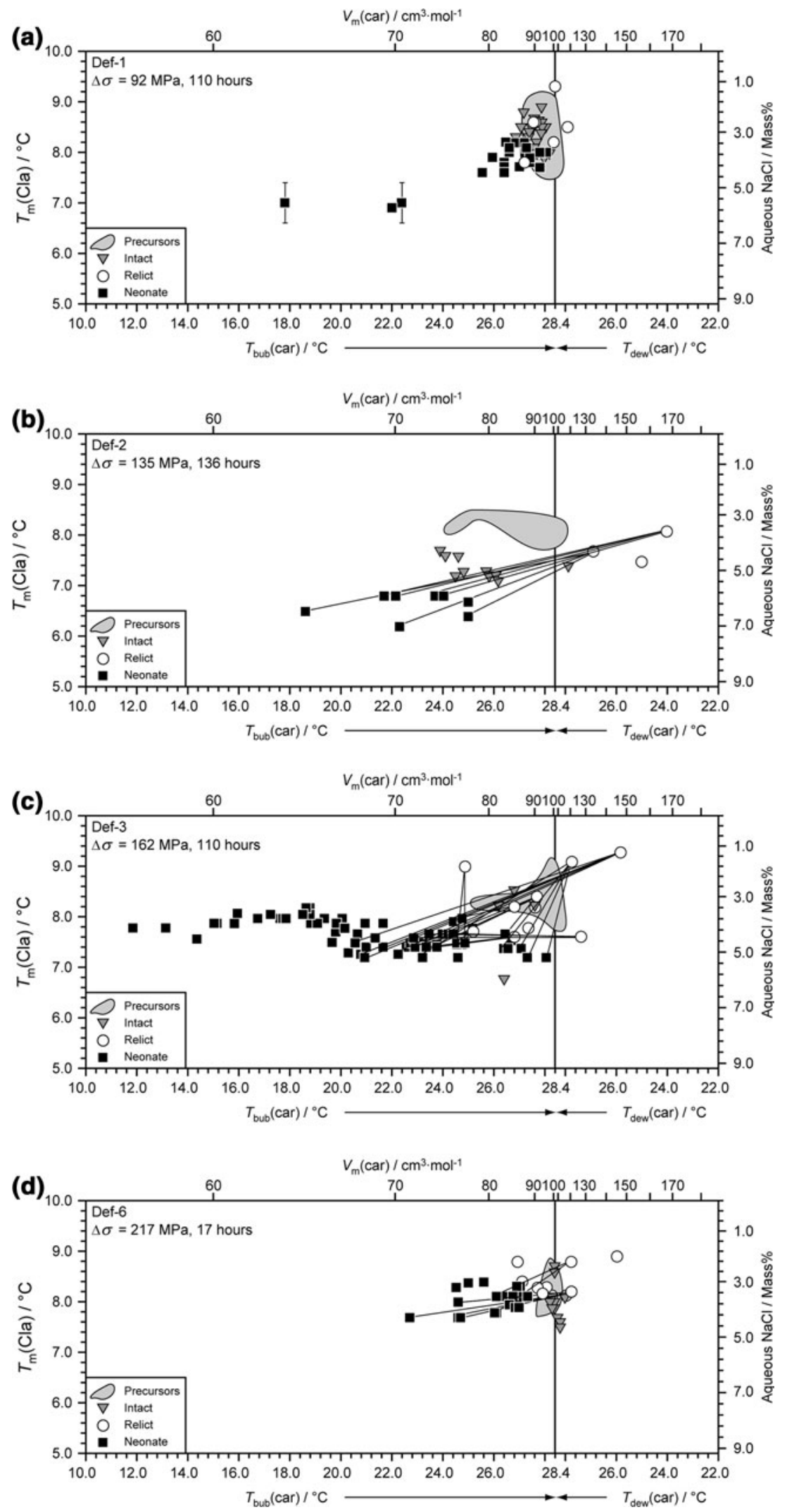
Table 3 Experimental conditions of deformation experiments at $700^{\circ} \mathrm{C}$

\begin{tabular}{llllllllr}
\hline Exp. & $\begin{array}{l}\text { Basel } \\
\text { lab no. }\end{array}$ & $\begin{array}{l}\mathrm{Fe}_{2} \mathrm{O}_{3} \\
\text { buffer }\end{array}$ & $\begin{array}{l}\text { Duration }^{\mathrm{a}} \\
\text { (hours) }\end{array}$ & $\begin{array}{l}\text { Strain }^{\mathrm{b}} \\
(\%)\end{array}$ & $\begin{array}{l}\text { Strain } \\
\text { rate }\left(\mathrm{s}^{-1}\right)\end{array}$ & $\begin{array}{l}\text { Confining } \\
\text { pressure } \\
\left(\sigma_{3}\right)(\mathrm{MPa})\end{array}$ & $\begin{array}{l}\text { Compressive } \\
\text { stress } \\
\left(\sigma_{1}\right)(\mathrm{MPa})\end{array}$ & $\begin{array}{l}\text { Nominal } \\
\text { dev. stress } \\
\Delta \sigma(\mathrm{MPa})\end{array}$ \\
\hline Def-1 & $163 \mathrm{AT}$ & Yes & 110 & $<0.2$ & $<5 \times 10^{-9}$ & 613 & 705 & 92 \\
Def-2 & 149AT & Yes & 136 & $0.1-0.3$ & $<6 \times 10^{-9}$ & 615 & 750 & 778 \\
Def-3 & 161AT & Yes & 110 & $0.3-0.6$ & $<2 \times 10^{-8}$ & 616 & 847 & 162 \\
Def-6 & 152AT & Yes & 17 & $?$ & $?$ & 630 & 217 \\
\hline
\end{tabular}

a Time at target $P-T$ conditions of experiment

b Plastic strain measured from difference in sample height before and after experiment

lower $\mathrm{H}_{2} \mathrm{O}$ and higher $\mathrm{NaCl}$ contents than their adjacent relict inclusions (indicated by tie-lines in Fig. 7).

\section{Fluid inclusions in vertical mode-I fractures}

Typically, the vertical loading fractures are "dry", but some are partly healed and contain myriads of tiny fluid inclusions. All fractures that host such inclusions appear to have cut through a pre-existing inclusion in the sample.

In sample Def-1, the fracture-hosted neonate inclusions are large enough to permit identification of two or three fluid phases at room temperature, and Raman analysis confirms the presence of a carbonic phase. The volume fraction of the carbonic phase varies widely between 0.4 and 0.8 in sample Def- 1 and can exceed 0.9 in sample Def2. The microthermometric results (Table 4) show that the aqueous phase has essentially the same salinity as the precursor inclusions (average $T_{\mathrm{m}}(\mathrm{cla})=3.9^{\circ} \mathrm{C}$; clathrate dissociates within the $\mathrm{Q}_{2}$ or $\mathrm{ClaL}_{\mathrm{aq}} \mathrm{L}_{\text {car }}$ assemblages). Values of $T_{\text {bub }}$ (car) vary over an extremely wide range, from -9.1 to $21.9^{\circ} \mathrm{C}$, much wider than the spreads of neonate inclusions in Fig. 6.

The range in volume fractions and the microthermometric features of the inclusions are diagnostic of heterogeneous entrapment (e.g. Diamond 2003). The cause and timing of the phase separation in the mode-I cracks is explained in the Electronic Supplement.

\section{Discussion}

The results presented earlier are internally consistent and reproducible. The most obvious differences between the experiments are due to the different durations and magnitudes of applied deviatoric stress. The results thus provide a basis to generalize the modifications of fluid inclusion composition and density induced by small degrees of uniaxial shortening. The purpose of the following discussion is to elucidate the mechanisms of these changes with a view to formulating criteria to interpret naturally deformed inclusions.
Changes in fluid inclusion composition

In general, the intact inclusions faithfully retain the bulk composition of the precursors. Only in experiment Def-2 is a slight systematic increase in salinity visible. Also the relict inclusions mostly preserve the composition of the precursors (again Def-2 shows an increase in salinity). In contrast, the neonate inclusions show quite dramatic, systematic shifts to lower $\mathrm{H}_{2} \mathrm{O}$ contents and higher gas and salt contents. Moreover, the higher the imposed deviatoric stress and the longer the duration of the experiment, the greater are these changes compared to the precursors. This correlation supports the idea that the application of deviatoric stress over extended periods of time is the driving force for the compositional changes. In most cases, the neonates have lower $\mathrm{H}_{2} \mathrm{O}$ and higher gas and salt contents than the relict inclusions that they surround. These systematic features raise the questions of how and why the compositions of the neonates change, while the intact and relict inclusions remain unchanged.

The first task is to identify which of the chemical components is mobile. This becomes evident by replotting the results in Fig. 7 into a ternary diagram (Fig. 8). The shift of the neonates from the precursor fields in all four experiments can be well explained by loss of $\mathrm{H}_{2} \mathrm{O}$ (vector marked with arrow in Fig. 8a), without the need to invoke mobility of the gas or salt components.

This deduction is consistent with previous studies. To our knowledge, no published experimental work has demonstrated that $\mathrm{N}_{2}, \mathrm{CO}_{2}$ or $\mathrm{NaCl}$ may be lost from fluid inclusions in quartz via diffusion. In contrast, several high$T$ experimental studies (Bakker and Jansen 1990, 1991; Hall and Sterner 1993; Sterner et al. 1995) have concluded that molecular $\mathrm{H}_{2} \mathrm{O}$ may diffuse into or out of fluid inclusions in quartz in response to gradients in the fugacity of $\mathrm{H}_{2} \mathrm{O}$. Whereas the physicochemical interaction between small, polar $\mathrm{H}_{2} \mathrm{O}$ molecules and the various dislocations and fracture surfaces in quartz is known to facilitate its mobility via pipe- or microcrack diffusion (e.g. McLaren et al. 1983, 1989; Kronenberg et al. 1986; Cordier and 


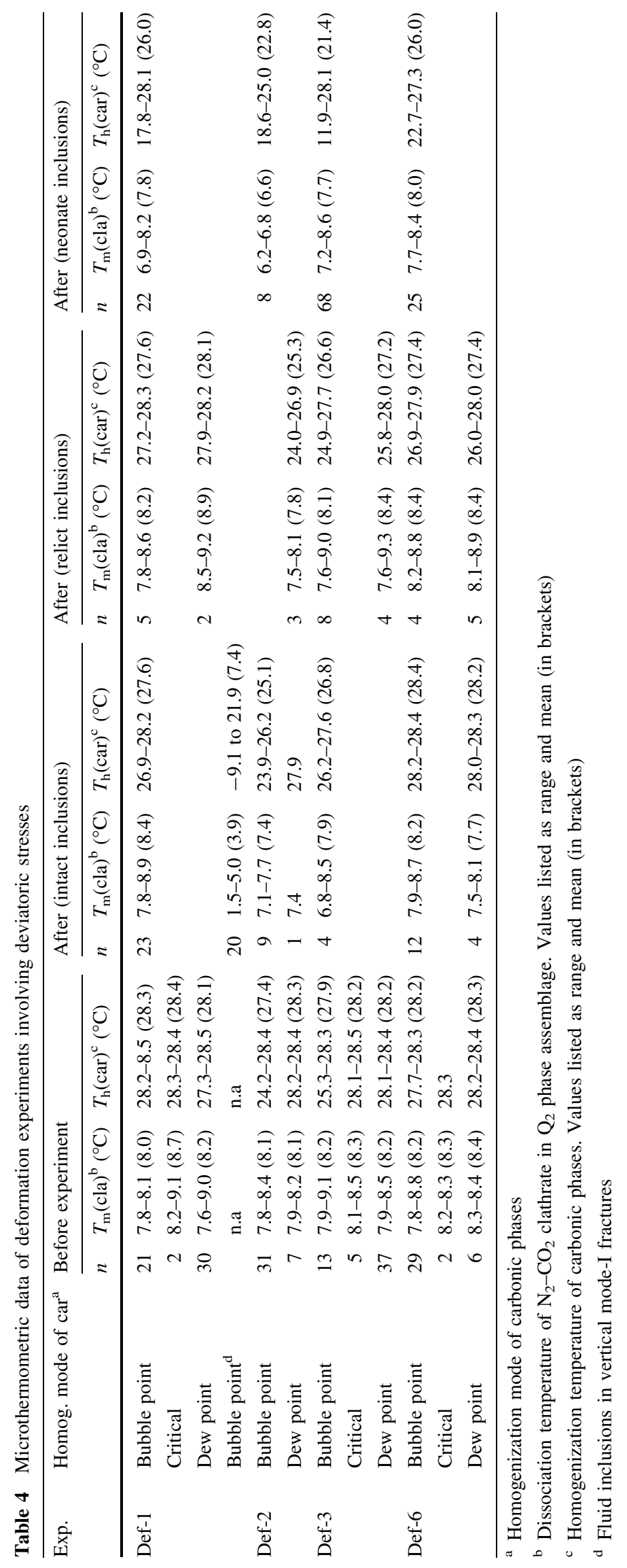




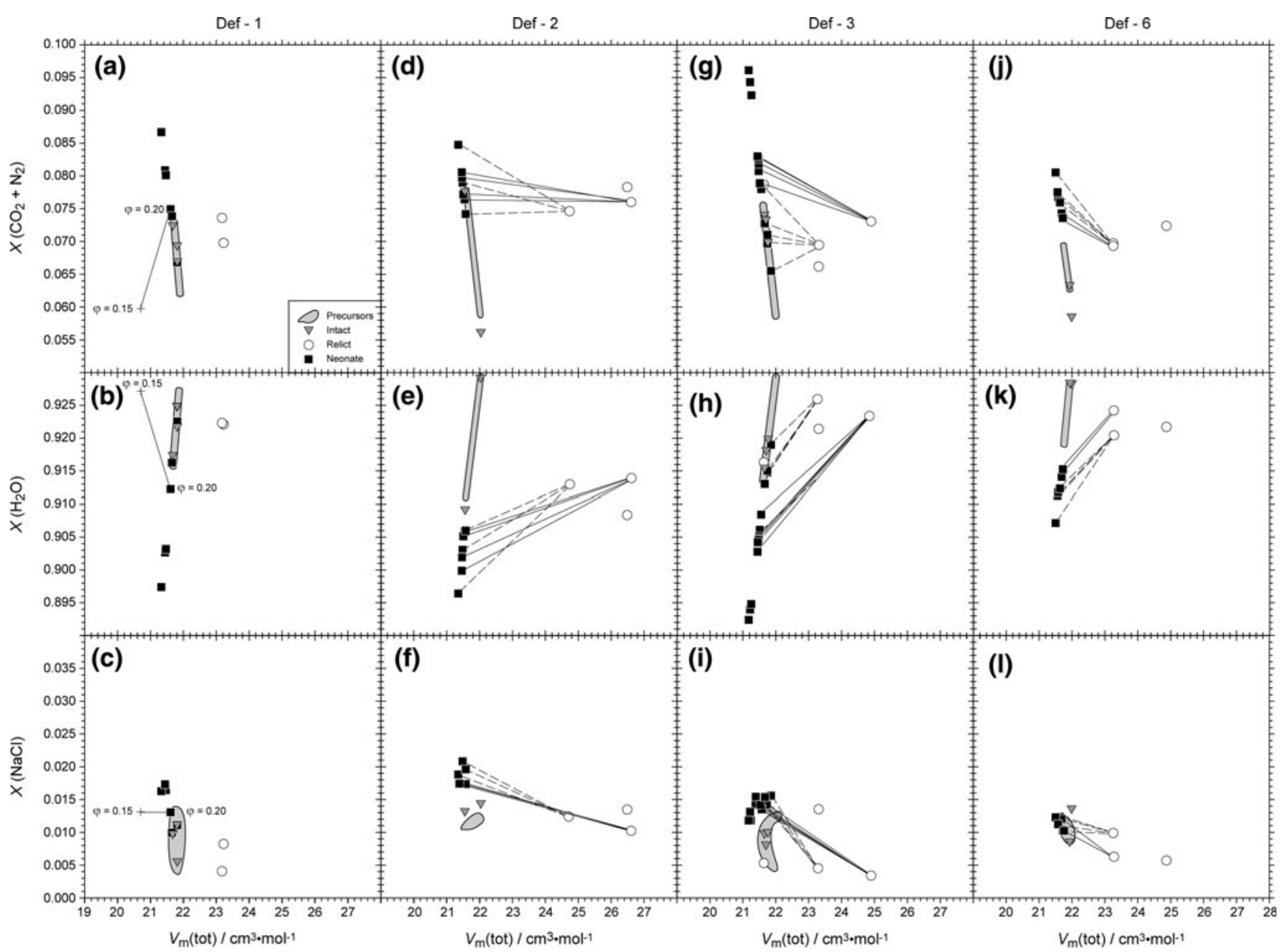

Fig. 7 Calculated bulk compositions, $X\left(\mathrm{CO}_{2}+\mathrm{N}_{2}\right), X\left(\mathrm{H}_{2} \mathrm{O}\right)$ and $X(\mathrm{NaCl})$ and molar volumes, $V_{\mathrm{m}}(\mathrm{tot})$, of representative fluid inclusions in deformation experiments involving deviatoric stresses. Values of $\varphi($ car $)=0.25-0.35$ have been used for the relict inclusions, and $\varphi($ car $)=0.20$ has been used for the precursor, intact

Doukhan 1989; Bakker and Jansen 1990, 1991, 1994; Kronenberg 1994), $\mathrm{N}_{2}, \mathrm{CO}_{2}$ and $\mathrm{NaCl}$ molecules appear to be immobile in quartz under conditions of overall electrical neutrality. Accordingly, the changes in composition of the neonate inclusions may be attributed solely to loss or gain of $\mathrm{H}_{2} \mathrm{O}$.

Loss of $\mathrm{H}_{2} \mathrm{O}$ via diffusion requires a significant gradient in $\mathrm{H}_{2} \mathrm{O}$ fugacity between the neonates and a specific local sink. Figure 9 shows $f\left(\mathrm{H}_{2} \mathrm{O}\right)$ calculated using the EoS of Bowers and Helgeson (1985) for the same Def-2 inclusions that are displayed in Fig. 7d-f. The bulk molar volumes, $V_{\mathrm{m}}$ (tot), have been adjusted as described in the next paragraph (Eq. 9). It can be seen that the low molar volume (high density) of the neonates implies much higher $f\left(\mathrm{H}_{2} \mathrm{O}\right)$ values at $700^{\circ} \mathrm{C}$ than those of the intact inclusions $\left(\Delta f\left(\mathrm{H}_{2} \mathrm{O}\right) \sim 80-200 \mathrm{MPa}\right)$ and of the relict inclusions $\left(\Delta f\left(\mathrm{H}_{2} \mathrm{O}\right)<400 \mathrm{MPa}\right)$, despite the lower $\mathrm{H}_{2} \mathrm{O}$ contents of the neonates. As the neonates have already lost and neonate inclusions. The effect of the uncertainty in $\varphi$ (car) between 0.15 and 0.20 for some neonates is illustrated by one example error bar. Tie-lines join data for inclusions that belong to the same cluster of relict and neonate inclusions

considerable $\mathrm{H}_{2} \mathrm{O}$ compared to their precursors, the high $f\left(\mathrm{H}_{2} \mathrm{O}\right)$ values in Fig. 9 must be residuals of even higher fugacities that presumably prevailed during the early stages of the experiments.

Now with clear evidence for high $f\left(\mathrm{H}_{2} \mathrm{O}\right)$ in the neonates, the potential sinks for $\mathrm{H}_{2} \mathrm{O}$ need to be identified. Many of the adjacent relict inclusions and the nearby intact inclusions evidently had lower $f\left(\mathrm{H}_{2} \mathrm{O}\right)$ at $700^{\circ} \mathrm{C}$, therefore these two types of inclusions may have acted as sinks for the $\mathrm{H}_{2} \mathrm{O}$ lost from the neonates. However, because both inclusion types are vastly larger than the neonates (typically by a volume factor of $10^{2}-10^{3}$ ), any gain of $\mathrm{H}_{2} \mathrm{O}$ may be undetectable. In fact, none of the intact or relict inclusions show measurable gains of $\mathrm{H}_{2} \mathrm{O}$ (Fig. 7).

A second sink for $\mathrm{H}_{2} \mathrm{O}$ could be the quartz host-crystal itself, but current understanding of $\mathrm{H}_{2} \mathrm{O}$ in quartz defects (e.g. Cordier et al. 1994; Cordier and Doukhan 1995) suggests that the amount of $\mathrm{H}_{2} \mathrm{O}$ that can be stored is 

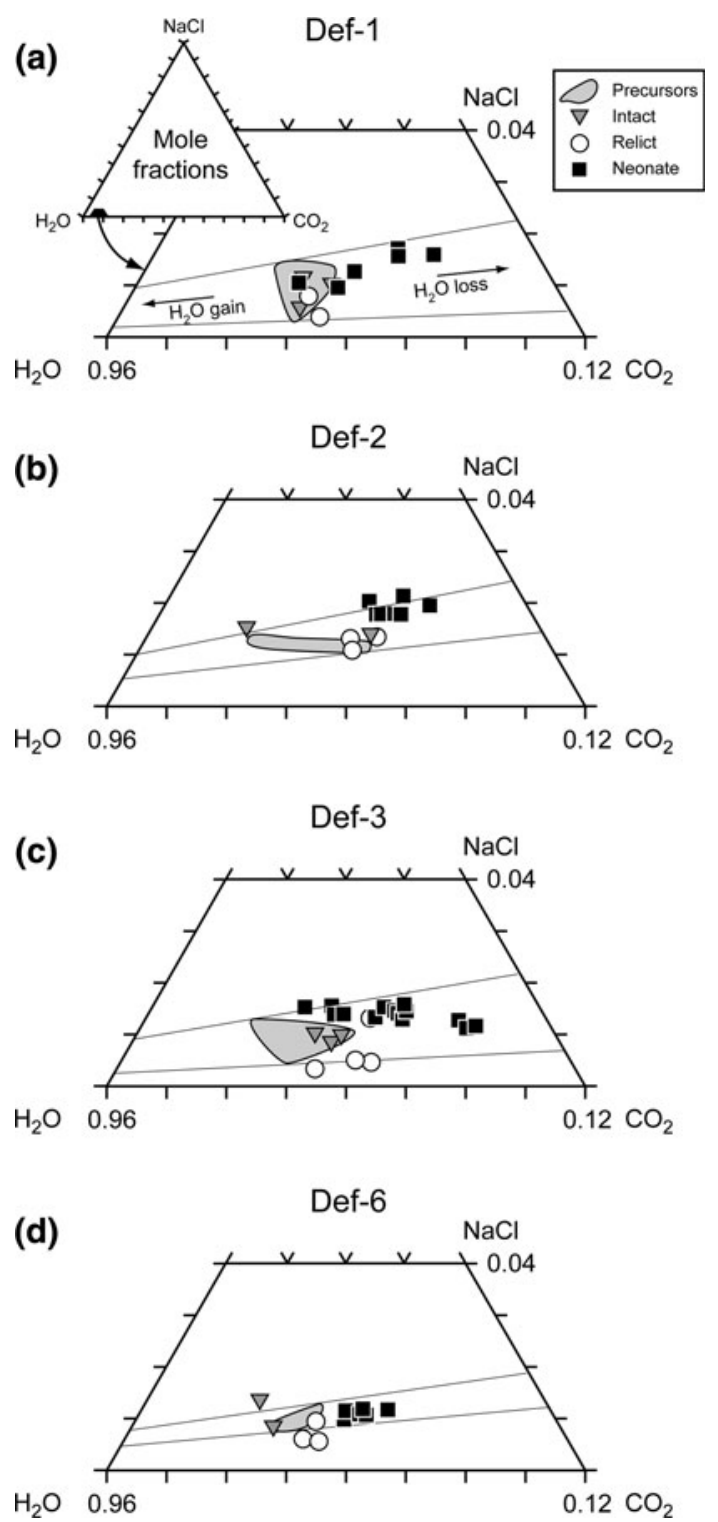

Fig. 8 Ternary $\mathrm{CO}_{2}-\mathrm{H}_{2} \mathrm{O}-\mathrm{NaCl}$ compositions (mole fractions) of fluid inclusions after deformation experiments involving deviatoric stresses. Black area in inset triangle shows region of expanded diagrams. Thin reference lines emanate from $\mathrm{H}_{2} \mathrm{O}$ apex, defining directions of possible loss and gain of $\mathrm{H}_{2} \mathrm{O}$. Positions of neonate inclusions indicate loss of $\mathrm{H}_{2} \mathrm{O}$ relative to precursor inclusions. a Def1, b Def-2, c Def-3 and d Def-6

minute-far lower than that needed to account for the observed changes in the neonate inclusions.

A third sink for $\mathrm{H}_{2} \mathrm{O}$ could be the exterior of the quartz samples, which are tightly encased in a gold jacket during the experiments. Although the $\mathrm{H}_{2}$-buffer reaction (8) generates water on the surfaces of the two alumina pistons inside the gold jacket (Fig. 3d), none of this water seems to have reached the surfaces of the quartz samples (the quartz is separated from the alumina by unwelded gold discs; Fig. 3d). Most of the mode-I fractures that formed in the

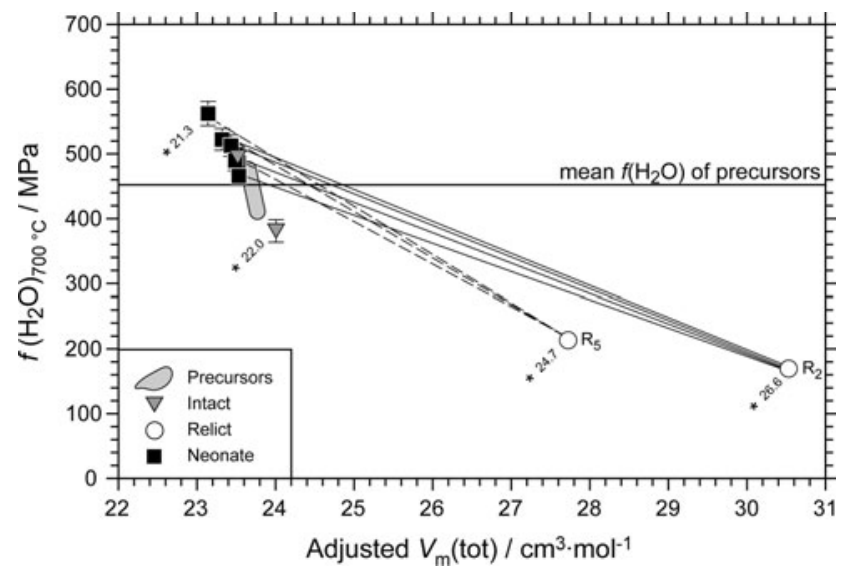

Fig. 9 Fugacity of $\mathrm{H}_{2} \mathrm{O}$ at $700^{\circ} \mathrm{C}$ in two clusters of dismembered inclusions from deformation experiment Def-2 $(\Delta \sigma=135 \mathrm{MPa}$, moderate strain). See text for "adjustment" of bulk molar volume, $V_{\mathrm{m}}$ (tot). Calculations made with EoS of Bowers and Helgeson (1995) with $\varphi($ car $)=0.20$ for neonate, precursor and intact inclusions, and $\varphi(\mathrm{car})=0.30$ and 0.35 for relict inclusions $R_{5}$ and $R_{2}$, respectively. Numbers with an asterisk are unadjusted $V_{\mathrm{m}}($ tot $)$ values $\left(\mathrm{cm}^{3} \mathrm{~mol}^{-1}\right)$ at room temperature. Tie-lines join dismembered fluid inclusions within the same cluster. The neonates have much higher $f\left(\mathrm{H}_{2} \mathrm{O}\right)$ than the precursor, intact and relict inclusions, and the relicts have the lowest values of all

quartz during heating and pressurization towards the run conditions are open and "dry". Had water wetted the quartz surfaces, the fractures would certainly have healed and trapped fluid inclusions (this process is the basis of the well established method of synthesizing fluid inclusions, e.g. Bodnar and Sterner 1987). Where inclusions did form in the fractures, their compositions show that they derive from rupturing of pre-existing $\mathrm{CO}_{2}-\mathrm{H}_{2} \mathrm{O}-\mathrm{NaCl}$ inclusions ("precursors"). The fact that the fracture-hosted inclusions were trapped in a heterogeneous state indicates much lower effective fluid pressures than $P_{\text {conf }}$ (discussed in detail in the Electronic Supplement). As well as demonstrating the absence of an external source of water, these same points of evidence also demonstrate that no appreciable $\mathrm{H}_{2} \mathrm{O}$ reached the sample surfaces from within the quartz. Therefore, despite the quartz surfaces being a potential sink for $\mathrm{H}_{2} \mathrm{O}$, and despite the nominally huge gradient in $f\left(\mathrm{H}_{2} \mathrm{O}\right)$ between the fluid inclusions and the unwetted quartz surfaces, it seems that diffusive transport was too slow relative to the duration of the experiments to permit loss of $\mathrm{H}_{2} \mathrm{O}$ to the sample exterior.

In conclusion, the most probable explanation is that, given the high fugacity gradient in Fig. 9, $\mathrm{H}_{2} \mathrm{O}$ diffused from the neonates into the adjacent relict inclusions at the length-scale of individual inclusion clusters. It is reasonable to assume that the $\mathrm{H}_{2} \mathrm{O}$ gained by the relict inclusions is undetectable. The dominant pathways for transport were most likely the abundant microcracks and dislocations that link the two inclusion types within individual clusters. 
Changes in molar volume (density) of the fluid inclusions

\section{Changes in molar volume of neonate inclusions}

In the foregoing, it is concluded that the difference in molar volume between the neonate and relict inclusions generates the gradient in $f\left(\mathrm{H}_{2} \mathrm{O}\right)$ which drives exchange of $\mathrm{H}_{2} \mathrm{O}$. The next question to be addressed is the origin of the differences in molar volume.

Based on the results of previous experimental studies involving hydrostatic underpressures $\left(P_{\text {inc }}<P_{\text {conf }}\right)$ (e.g. Sterner and Bodnar 1989), we expect the precursor inclusions to become denser as they adapt to a new mechanical $(P-V)$ equilibrium commensurate with the deviatoric stress state of the host quartz. However, the end-point of the new $P-V$ equilibrium is not obvious a priori. For instance, the fluid may adopt a molar volume compatible with the mean stress at $700^{\circ} \mathrm{C}$, or with some other stress value. The bulk $V_{\mathrm{m}}-X$ properties calculated for the intact, relict and neonate inclusions (e.g. Fig. 7) all correspond to defined fluid pressures at $700^{\circ} \mathrm{C}$. These pressures, $P_{\text {inc }}$, can be reconstructed using an appropriate EoS by assuming quasi-isochoric behaviour of the inclusions from $T_{\mathrm{h}}$ (car) up to $700^{\circ} \mathrm{C}$. Thus, comparison of the $P_{\text {inc }}$ values with the $\sigma_{1}$ and $\sigma_{3}$ stresses imposed during the experiments should in principle reveal the end-point of reequilibration of the inclusions.

Calculations of $P_{\text {inc }}$ at $700^{\circ} \mathrm{C}$ were duly made for precursor, intact, relict and neonate inclusions in experiments Def-1, Def-2, Def-3 and Def-6. Nitrogen was lumped with $\mathrm{CO}_{2}$ to calculate ternary $\mathrm{CO}_{2}-\mathrm{H}_{2} \mathrm{O}-\mathrm{NaCl}$ isochores with the Bowers and Helgeson (1985) and Duan et al. (1995) EoS. The modification of the Bowers and Helgeson (1985) EoS by Bakker (1999) was also used to take explicit account of $\mathrm{N}_{2}$, but the pressures were not significantly different for the very small bulk $X\left(\mathrm{~N}_{2}\right)$ values involved. Corrections were made for the expansivity and compressibility of $\alpha$-quartz between $P_{\text {inc }}$ at $700^{\circ} \mathrm{C}$ and $T_{\mathrm{h}}(\mathrm{car})$ at $P_{\mathrm{h}}(\mathrm{car})$ using the EoS of Hosieni et al. (1985).

The results of these calculations pose a conflict in our experimental method. The value of $\sigma_{3}=600 \mathrm{MPa}$ is compatible with the calculated range of pressures extrapolated for the complete set of inclusions reported by Diamond (1990) at the Brusson locality (Fig. 1). However, the $P_{\text {inc }}$ values calculated for the specific set of precursor inclusions used in the experiments lie between 750 and $820 \mathrm{MPa}$, some 150-220 MPa higher than $\sigma_{3}$ (or 100$170 \mathrm{MPa}$ applying the maximum uncertainty in $\sigma_{3}$ ). Nevertheless, the hydrostatic scoping experiments Hyd-5 and Hyd-6 both showed microstructural equilibration with $P_{\text {conf }}=600 \mathrm{MPa}$ (Fig. 4 in Tarantola et al. 2010), and it was this evidence that lead us to assume that $\Delta P=0$ at $600 \mathrm{MPa}$ and $700^{\circ} \mathrm{C}$. We have carefully reexamined our experimental method and the approach and assumptions made in calculating $P_{\text {inc }}$ from the isochores, but we have been unable to resolve this conflict. As our prime aim is to evaluate the effects of deviatoric stress, $\Delta \sigma$, in general, rather than the effects of absolute stress, this inconsistency is not crucial to our study. There seems to be more leeway in the EoS extrapolation of the isochores to high temperature than in the measurement of maximum pressure in the Griggs piston-cylinder apparatus. Consequently, we have chosen to accept that $\sigma_{3}=600 \pm 50 \mathrm{MPa}$ truly represents the experiments.

To evaluate the internal pressures of the modified inclusions, we have adjusted the calculated isochores such that the mean precursor isochore intersects the corresponding confining pressure $\left(\sigma_{3}\right.$; Table 2$)$ at $700^{\circ} \mathrm{C}$. The fan of precursor isochores derived from this mean is displayed in light shading in Fig. 10. To preserve the relative difference in pressure between the neonate and precursor inclusions, the EoS pressures calculated for the neonates at $700^{\circ} \mathrm{C}$ were adjusted as follows:

$P_{\text {neonate }}($ adjusted $)=\frac{P_{\text {neonate }}(\mathrm{EoS})}{P_{\text {precursor }}(\mathrm{EoS})} \cdot \sigma_{3}[\mathrm{MPa}]$

The resulting shifts in internal pressures are indicated in Fig. 10. Points labelled 1 show $P_{\text {inc }}$ of the densest neonate inclusions based on EoS calculations and points labelled 2 show the adjusted values. The adjusted pressures were used to construct the fans of isochores of the neonate inclusions, as shown in dark shading in Fig. 10.

In experiments Def-1 and Def-3 (Fig. 10a, c), the isochores of the neonates span the entire range of fluid pressures between $\sigma_{1}$ and $\sigma_{3}$. In the other long-duration experiment, Def-2 (Fig. 10b), the densest neonates approach $\sigma_{1}$ quite closely, whereas in the short-duration experiment Def-6 (Fig. 10c), the highest pressure in a neonate inclusion lies at about a third of the interval to $\sigma_{1}$. This suggests that the neonates do not initially form with high densities, but that they increase their densities with time. It also seems likely that the end-point of this density evolution is equilibrium with $\sigma_{1}$, rather than with the mean stress $\left(\sigma_{1}+2 \sigma_{3}\right) / 3$.

\section{Changes in molar volume of relict inclusions}

The relict inclusions generally have not changed composition with respect to the precursors, but many of them have increased their molar volumes. It follows that these relicts have expanded during the experiments. This conclusion agrees with the observed correlation between $\varphi\left(\right.$ car) and $V_{\mathrm{m}}$ (car). Calculations of volume expansion of a model precursor (Fig. 11; details of calculation in 
Fig. 10 Comparison of adjusted isochores of precursor inclusions (light shading) and neonate inclusions (dark shading) in deformation experiments involving deviatoric stresses. Open squares show magnitude of $\sigma_{3} \pm 50 \mathrm{MPa}$ at $700^{\circ} \mathrm{C}$; filled squares show magnitude of $\sigma_{1} \pm 10 \%$ relative to $\sigma_{3}$ at $700^{\circ}$ C. Points 1 and 2 show the adjustment of maximum $P_{\text {neonate }}$ at $700^{\circ} \mathrm{C}$, according to Eq. 9 (see text). The adjusted pressures of neonates span the range between $\sigma_{3}$ and $\sigma_{1}$, the highest values being approximately equal to the absolute value of $\sigma_{1}$. a Experiment Def-1. b Experiment Def-2. c Experiment Def-3. d Experiment Def-6 (a) 1100

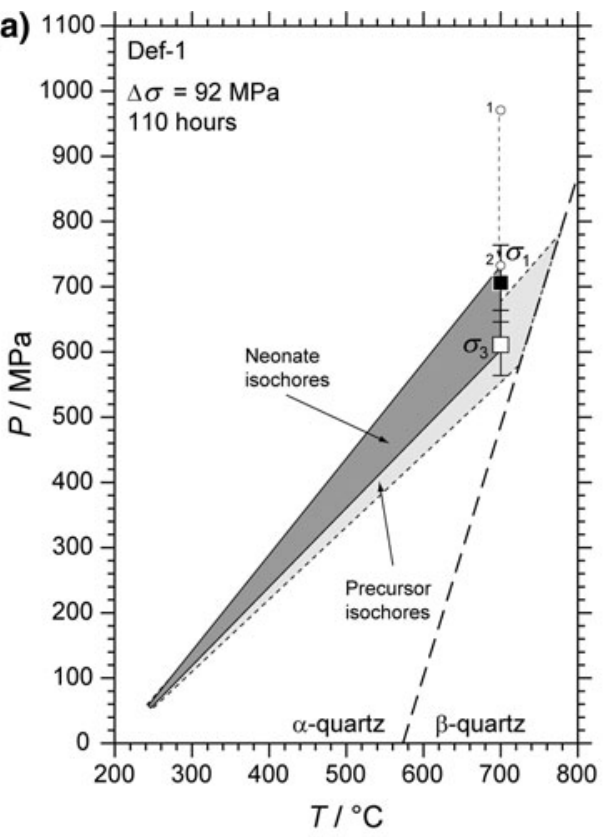

(c)

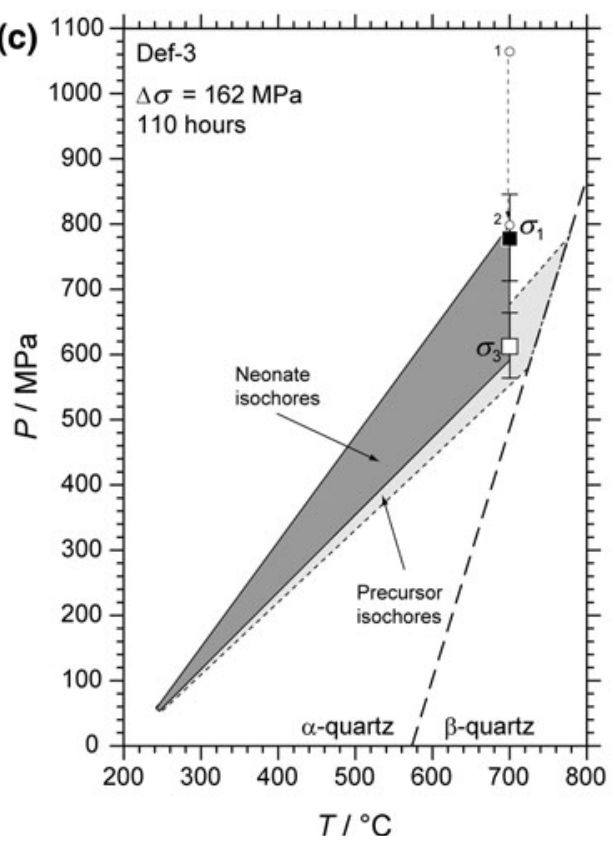

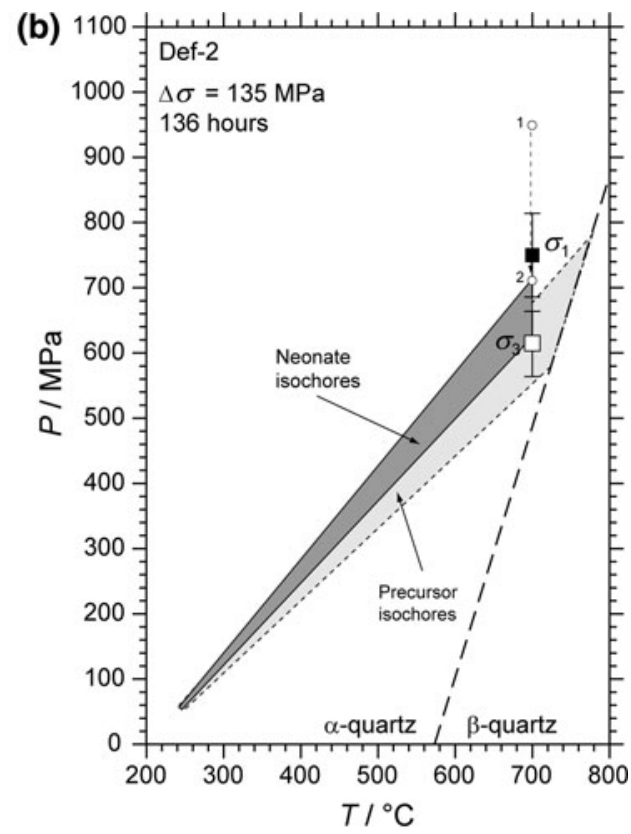

(d)

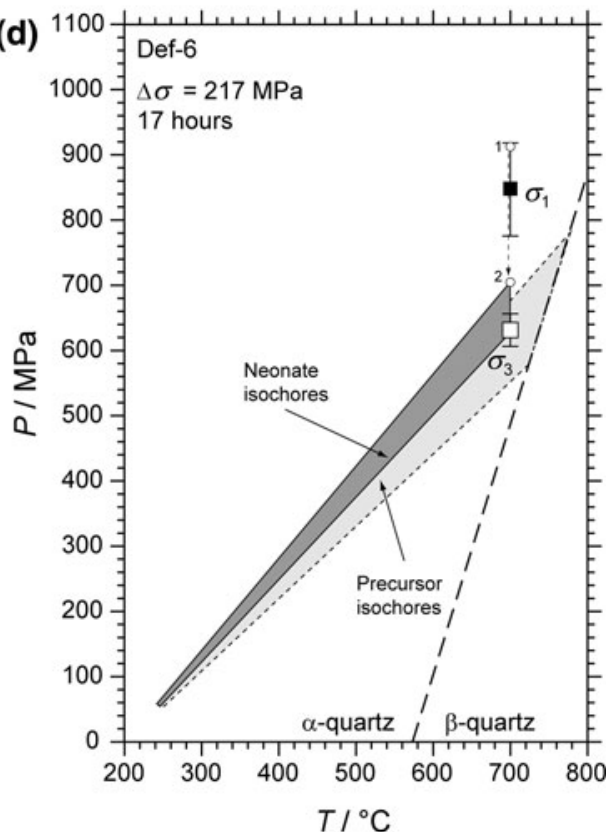

“Appendix 2") predict correlations between $\varphi$ (car), $V_{\mathrm{m}}$ (car) and $V_{\mathrm{m}}$ (tot) that match the observations quite well. The maximum observed $\varphi($ car $)$ and $V_{\mathrm{m}}$ (car) values of around 0.35 and $170 \mathrm{~cm}^{3} \mathrm{~mol}^{-1}$, respectively, suggest that some inclusions expanded by as much as $20 \%$ (Fig. 11b). Presumably the microcracking observed around the relicts permitted this expansion to occur. Nevertheless, any expansion at all is remarkable considering that the samples were subjected to positive deviatoric stresses $\left(\sigma_{1}>P_{\text {inc }}\right)$. The high molar volumes of the relicts correspond to internal pressures as low as $400 \mathrm{MPa}$ during the experiments, i.e. some $200 \mathrm{MPa}$ below the value of $\sigma_{3}$. Thus, contrary to expectation, the final state reached by the relict inclusions during the deformation process lies further from $P-V$ equilibrium than the initial (precursor) state.

There is no evidence from the experiments that the pressure drop associated with volume expansion was sufficient to cause phase exsolution (also termed heterogenization or unmixing or boiling) in the relict inclusions (in contrast to the vertical mode-I fractures, as described in the Electronic Supplement). In nature, however, it is conceivable that phase exsolution could take place if the quartz 

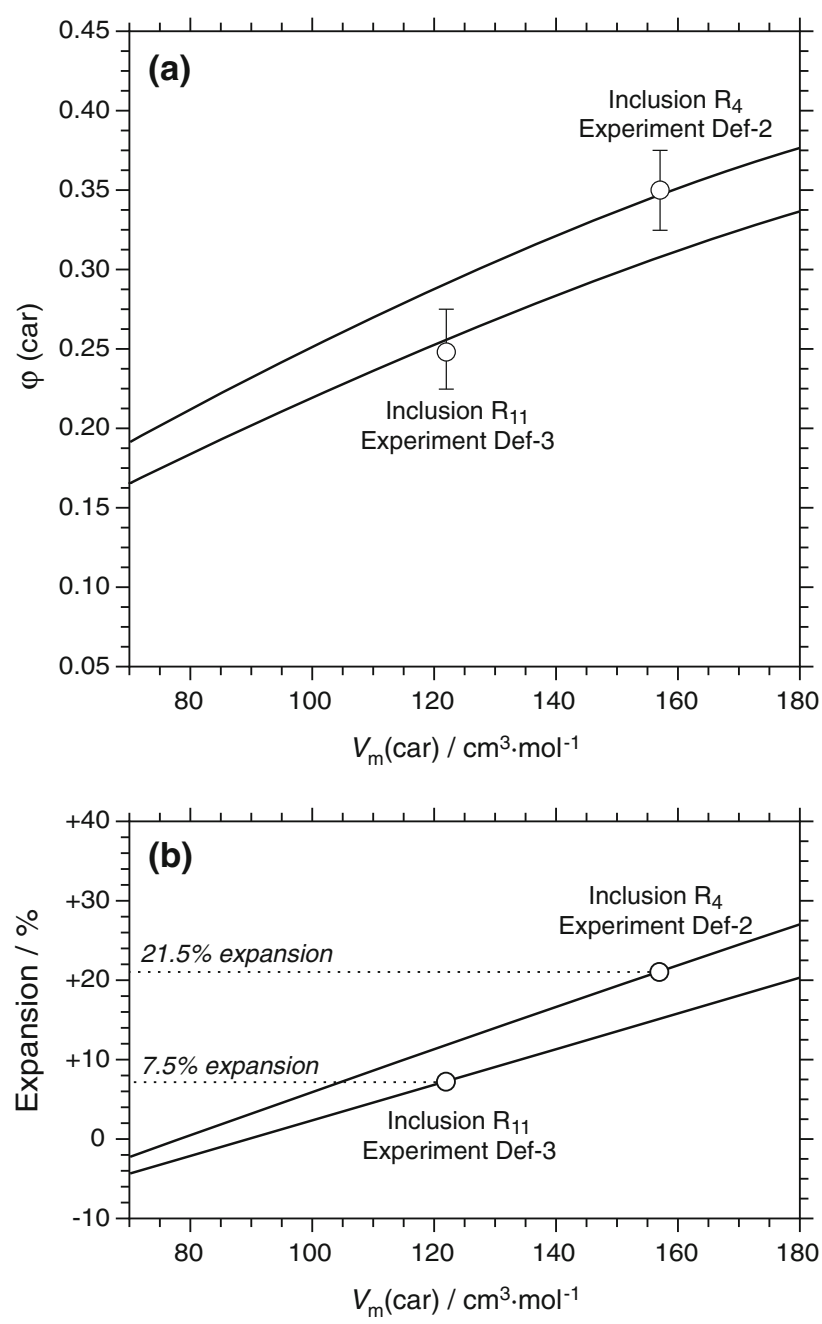

Fig. 11 Test of hypothesis that relict inclusions have expanded during deformation experiments involving deviatoric stresses. Curves show predicted relationships for the range of bulk compositions observed in relict inclusions. Calculations made according to "Appendix 2". a Relationships between measurable parameters: molar volume of carbonic phase, $V_{\mathrm{m}}$ (car), and volume fraction of carbonic phase, $\varphi$ (car). b Predicted relationship between $V_{\mathrm{m}}$ (car) and amount of expansion of relict inclusions (\%). Data points with error bars are examples of observations from relicts in experiments Def-2 and Def-3. Agreement between predictions and observations is consistent with expansion hypothesis

deformation occurs at lower lithostatic pressures (shallower levels in the crust), closer to the miscibility boundary of the specific $\mathrm{CO}_{2}-\mathrm{H}_{2} \mathrm{O}-\mathrm{NaCl}$ fluid. This process may be relevant to the occurrence of almost pure carbonic fluid inclusions in shear-zone hosted quartz veins (e.g. Schwartz et al. 1992; Klemd et al. 1997; Schmidt Mumm et al. 1997).

Mechanisms of fluid inclusion modifications

Our understanding of the mechanisms that result in the observed modifications of the inclusion shapes and $V_{\mathrm{m}}-X$ properties is still incomplete. In the following, we summarize our conclusions so far in the form of a conceptual model.

Application of deviatoric stress causes stress concentration radially normal to $\sigma_{1}$ at acute angles in the walls of the precursor fluid inclusions. This generates brittle microcracks that propagate into the surrounding quartz by parting the crystallographic cleavage planes oriented subparallel to the $\sigma_{3}$ plane. Crack propagation stops when the elastic component of the strain is relaxed by a net volume increase (by up to 20\%) of the inclusion. The fluid injected into the cracks promotes quartz healing by dissolution at sites of high interfacial energy (e.g. sharp irregularities) and by adjacent reprecipitation. Branches of fluid are first isolated in this crack-healing process and with time myriads of tiny, subequant to equant neonate inclusions become isolated as the branches neck down, locally minimizing interfacial energy. The fluid density of the neonates is initially similar to that of the expanded relict inclusions, but with time the density of the neonates increases towards $P-V$ equilibrium with the maximum applied stress, $\sigma_{1}$. The compression of the fluid that elevates the density seems to be facilitated by crystal-plastic dislocation glide of the quartz in the vicinity of the healed cracks. Presumably this plasticity is stimulated by $\mathrm{H}_{2} \mathrm{O}$-weakening of the dislocation-rich "wetted" quartz adjacent to the cracks (Fitz Gerald et al. 1991). The compression of the neonates significantly raises their $f\left(\mathrm{H}_{2} \mathrm{O}\right)$, which drives diffusion of $\mathrm{H}_{2} \mathrm{O}$ out into the surroundings. The salt and gas contents of the neonates thereby increase passively with time. Owing to the low internal pressures of the relict inclusions, they may act as sinks for the diffusing $\mathrm{H}_{2} \mathrm{O}$. The plastic deformation that nucleates around the neonate inclusions progressively spreads out into the surrounding lattice via basal and prism glide systems, leading to bands of discrete c-axis misorientation and undulatory optical extinction in inclusion-bearing domains of the sample (cf. Fitz Gerald et al. 1991).

\section{Conclusions}

This experimental study has provided a coherent picture of fluid inclusion modifications induced by low crystal-plastic strain at high temperature. The companion paper (Tarantola et al. 2010) provides arguments that the experimental results are transferable to nature. Thus, several guidelines can be established regarding the information obtainable from fluid inclusions in natural, low-strain, sheared quartz samples. These guidelines are formulated in terms of the nomenclature for deformed inclusions given in Fig. 4.

Very small shear strains impart irregular shapes to the intact inclusions, but their compositions and densities 
remain unperturbed. Higher strains may cause a slight increase in salt and gas contents owing to diffusive loss of $\mathrm{H}_{2} \mathrm{O}$ adjacent to relict inclusions. Microthermometric analyses of the intact inclusions in low-strain samples should therefore allow the pre-deformation $V_{\mathrm{m}}-X$ properties of the precursors to be reconstructed to a close approximation.

Large irregularly shaped relicts of the precursor inclusions sit at the centre of the clusters of neonates. According to our current understanding, these relicts faithfully record the composition of the precursors but in addition to shape changes they may have undergone significant volume expansion (despite the compressive deviatoric stress). In general, their densities (and hence their isochores) bear no relation to any pressure- or stress-state experienced by the rock sample during the deformation event. Therefore, their densities cannot be used to gain meaningful information on the free paleofluids or on the magnitudes of the principal shear stresses.

The neonate inclusions typically have lost significant $\mathrm{H}_{2} \mathrm{O}$ via diffusion and hence their salt and gas contents are passively increased in comparison to the precursor inclusions. As such, the chemical compositions of the neonates are artefacts of the deformation process and they do not record the properties of any free hydrothermal or metamorphic fluid that initially existed at the grain boundaries of the quartz sample. In contrast, the densities of the neonates have the potential to yield useful information. They span a very wide range, the highest of which may be equal to the density in $P-V$ equilibrium with the principal compressive stress, $\sigma_{1}$, during shear deformation. Therefore, reconstruction of the isochores of the densest neonates may help to estimate the absolute stress of $\sigma_{1}$ if the temperature of deformation is known.

Acknowledgments This study was supported by Swiss National Science Foundation grants 200020-111834 and 200020-122131 to L. W. Diamond. Anina Caviezel kindly assisted with spindle-stage measurements. The authors are grateful to two anonymous journal reviewers for their helpful comments and to Jacques Touret for editorial advice.

\section{Appendix 1: Measurement of volume fraction of carbonic phase in a precursor inclusion}

Following the method of Bakker and Diamond (2006), the volume fraction of the carbonic phases in an example precursor inclusion can be determined from the two data plots in Fig. 12. Figure 12a displays triplicate measurements of the total projected area of the inclusion as a function of rotation angle of the spindle stage. Figure $12 \mathrm{~b}$ displays triplicate measurements of the area fraction of the carbonic phase as a function of rotation angle of the spindle stage. The maximum in the data array in Fig. 12a lies at the rotation angle $12.5^{\circ}$ (marked by an arrow). This angle, when intersected with the area-fraction curve in Fig. 12b, indicates the area fraction (0.193) which most closely approximates the numerical value of the volume fraction. The method carries an uncertainty of $\pm 4 \%$ relative. Thus, the result for this example is $\varphi($ car $)=0.193 \pm 0.008$.
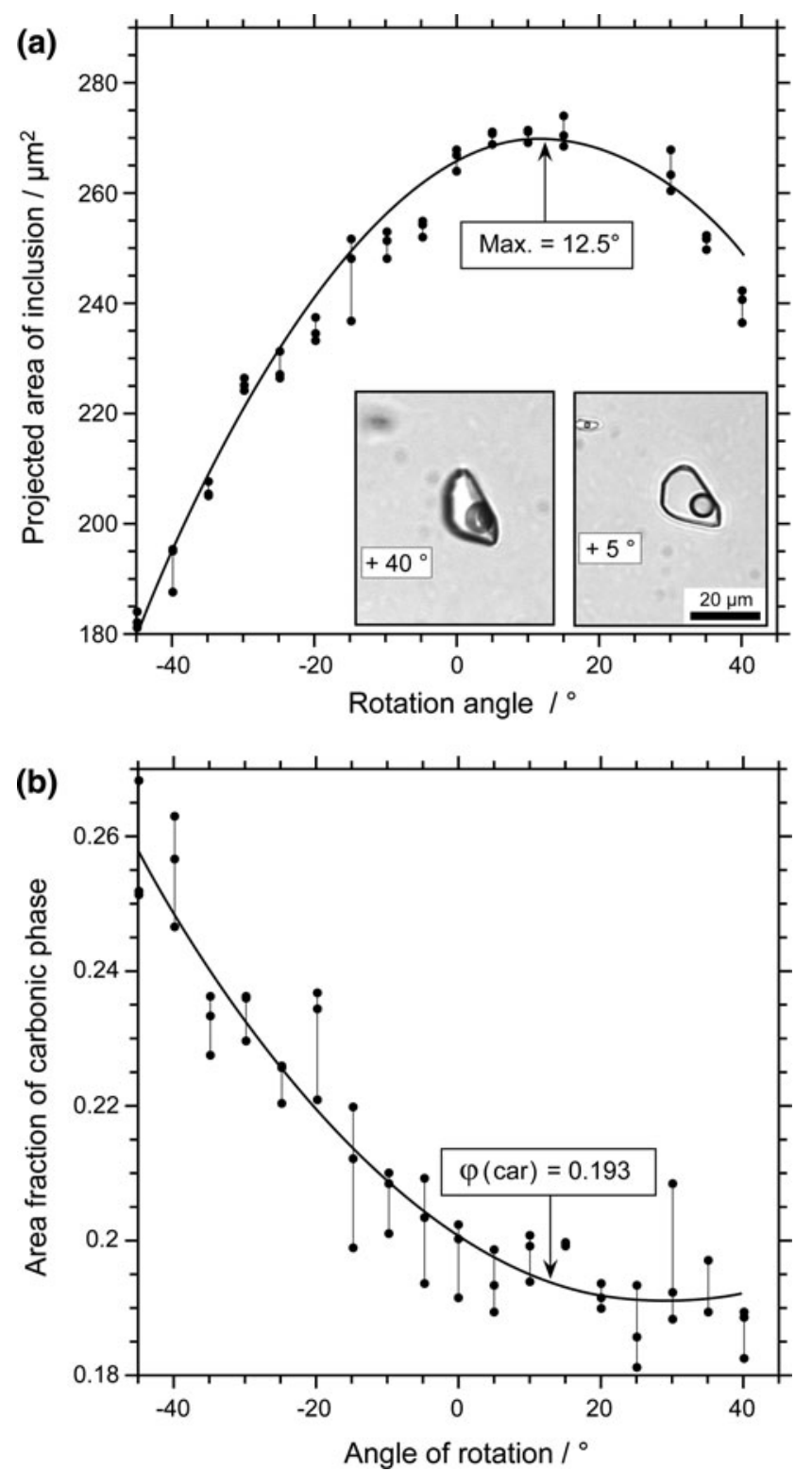

Fig. 12 Estimation of the volume fraction of the carbonic phase, $\varphi(\mathrm{car})$, at room temperature in an example inclusion using the method of Bakker and Diamond (2006). a Projected area of the inclusion versus angle of rotation in the spindle stage. $\mathbf{b}$ Area fraction of the carbonic phase versus angle of rotation in the spindle stage. See text for explanation 


\section{Appendix 2: Calculation of relationship between $V_{m}$ (car) and $\varphi($ car) for an expanding fluid inclusion}

To test the hypothesis that the relict fluid inclusions have expanded their volumes at constant composition, the relationship between the observable parameters $V_{\mathrm{m}}$ (car) and $\varphi($ car $)$ can be calculated as a function of volume expansion. For a fluid inclusion of fixed composition, the mole fraction of carbonic phase can be obtained by rearranging Eq. 5 :

$X_{\text {car }}^{\text {tot }}=1-\frac{X_{\mathrm{H}_{2} \mathrm{O}}^{\mathrm{tot}}}{X_{\mathrm{H}_{2} \mathrm{O}}^{\mathrm{aq}}}$

This value can be inserted into a rearrangement of Eq. 2 to yield the molar volume of the carbonic phase:

$V_{\mathrm{m}}(\mathrm{car})=\frac{V_{\mathrm{m}}(\mathrm{tot})-V_{\mathrm{m}}(\mathrm{aq})}{X_{\mathrm{car}}^{\mathrm{tot}}}+V_{\mathrm{m}}(\mathrm{aq})$,

where for simplification $V_{\mathrm{m}}(\mathrm{aq})$ is held constant. Input values of $V_{\mathrm{m}}$ (tot) are generated by multiplying the initial (measured) $V_{\mathrm{m}}$ (tot) by an arbitrary factor to simulate expansion of the inclusion volume. For example, $10 \%$ expansion increases an initial $V_{\mathrm{m}}$ (tot) of $22 \mathrm{~cm}^{3} \mathrm{~mol}^{-1}$ to a final $V_{\mathrm{m}}$ (tot) of $24.2 \mathrm{~cm}^{3} \mathrm{~mol}^{-1}$. Solution of Eq. 10 for a range of $V_{\mathrm{m}}$ (tot) yields the model relationship between $V_{\mathrm{m}}(\mathrm{aq})$ and the hypothesized volume expansion (curve in Fig. 11b).

Inserting the appropriate constant $V_{\mathrm{m}}(\mathrm{aq})$ and the $V_{\mathrm{m}}$ (car) value calculated from Eq. 10 into the following expression (Eq. 5 in Diamond 2001):

$\varphi(\mathrm{car})=\frac{\left(\frac{V_{\mathrm{m}}(\mathrm{aq})}{V_{\mathrm{m}}(\mathrm{tot})}-1\right)}{\left(\frac{V_{\mathrm{m}}(\mathrm{aq})}{V_{\mathrm{m}}(\mathrm{car})}-1\right)}$,

yields the model relationship between $V_{\mathrm{m}}$ (car) and $\varphi$ (car) (curve in Fig. 11a), which can be compared with the observations.

\section{References}

Akinfiev NN, Diamond LW (2003) Thermodynamic description of aqueous nonelectrolytes at infinite dilution over a wide range of state parameters. Geochim Cosmochim Acta 67(4):613-629

Akinfiev NN, Diamond LW (2010) Thermodynamic model of aqueous $\mathrm{CO}_{2}-\mathrm{H}_{2} \mathrm{O}-\mathrm{NaCl}$ solutions from -22 to $100^{\circ} \mathrm{C}$ and from 0.1 to $100 \mathrm{MPa}$. Fluid Phase Equilib (submitted)

Bakker RJ (1999) Adaptation of the Bowers and Helgeson (1983) equation of state to the $\mathrm{H}_{2} \mathrm{O}-\mathrm{CO}_{2}-\mathrm{CH}_{4}-\mathrm{N}_{2}-\mathrm{NaCl}$ system. Chem Geol 154(1-4):225-236

Bakker RJ (2003) Package FLUIDS 1. Computer programs for analysis of fluid inclusion data and for modelling bulk fluid properties. Chem Geol 194:3-23

Bakker RJ, Diamond LW (2006) Estimation of volume fractions of liquid and vapor phases in fluid inclusions, and definition of inclusion shapes. Am Mineral 91:635-657
Bakker RJ, Jansen JBH (1990) Preferential water leakage from fluid inclusions by means of mobile dislocations. Nature 345:58-60

Bakker RJ, Jansen JBH (1991) Experimental post-entrapment water loss from synthetic $\mathrm{CO}_{2}-\mathrm{H}_{2} \mathrm{O}$ inclusions in natural quartz. Geochim Cosmochim Acta 55:2215-2230

Bakker RJ, Jansen JBH (1994) A mechanism for preferential $\mathrm{H}_{2} \mathrm{O}$ leakage from fluid inclusions in quartz, based on TEM observations. Contrib Mineral Petrol 116:7-20

Bodnar RJ, Sterner SM (1987) Synthetic fluid inclusions. In: Ulmer GC, Barnes HL (eds) Hydrothermal experimental techniques. Wiley, New York, pp 423-457

Bowers TS, Helgeson HC (1985) FORTRAN programs for generating fluid inclusion isochores and fugacity coefficients for the system $\mathrm{H}_{2} \mathrm{O}-\mathrm{CO}_{2}-\mathrm{NaCl}$ at high pressures and temperatures. Comput Geosci 11:203-213

Cordier P, Doukhan JC (1989) Water in quartz; solubility and influence on ductility. Eur J Min 1:221-237

Cordier P, Doukhan JC (1995) Plasticity and dissociation of dislocations in water-poor quartz. Phil Mag A 72(2):497-514

Cordier P, Doukhan JC, Ramboz C (1994) Influence of dislocations on water leakage from fluid inclusions in quartz: a quantitative reappraisal. Eur J Min 6:745-752

Diamond LW (1990) Fluid inclusion evidence for $P-V-T-X$ evolution of hydrothermal solutions in late-Alpine gold-quartz veins at Brusson, Val d'Ayas, Northwest Italian Alps. Am J Sci 290:912958

Diamond LW (1992) Stability of $\mathrm{CO}_{2}$-clathrate-hydrate $+\mathrm{CO}_{2}$ liquid $+\mathrm{CO}_{2}$ vapour + aqueous $\mathrm{KCl}-\mathrm{NaCl}$ solutions: experimental determination and application to salinity estimates of fluid inclusions. Geochim Cosmochim Acta 56:273-280

Diamond LW (1994) Salinity of multivolatile fluid inclusions determined from clathrate hydrate stability. Geochim Cosmochim Acta 58:19-41

Diamond LW (2001) Review of the systematics of $\mathrm{CO}_{2}-\mathrm{H}_{2} \mathrm{O}$ fluid inclusions. Lithos 55:69-99

Diamond LW (2003) Introduction to gas-bearing aqueous fluid inclusions. In Samson IM, Anderson AJ, Marshall DD (eds) Fluid inclusions: analysis and interpretation. Min Ass Canada, short course series volume 32:101-158

Duan ZH, Møller N, Weare JH (1995) Equation of state for the $\mathrm{NaCl}-$ $\mathrm{H}_{2} \mathrm{O}-\mathrm{CO}_{2}$ system: prediction of phase equilibria and volumetric properties. Geochim Cosmochim Acta 59(14):2869-2882

Fitz Gerald JD, Boland JN, McLaren AC, Ord A, Hobbs BE (1991) Microstructures in water-weakened single crystals of quartz. J Geophys Res 96(B2):2139-2155

Gehrig M (1980) Phasengleichgewichte und PVT-Daten ternären Mischungen aus Wasser, Kohlendioxid und Natriumchlorid bis $3 \mathrm{kbar}$ und $550^{\circ} \mathrm{C}$. Doctoral Dissertation, Univ. Karlsruhe

Hall DL, Sterner SM (1993) Preferential water loss from synthetic fluid inclusions. Contrib Mineral Petrol 114:489-500

Hall DL, Sterner SM (1995) Experimental diffusion of hydrogen into synthetic fluid inclusions in quartz. J Metamorph Geol 13:345355

Hollister LS (1988) On the origin of $\mathrm{CO}_{2}$-rich fluid inclusions in migmatites. J Metamorph Geol 6:467-474

Hollister LS (1990) Enrichment of $\mathrm{CO}_{2}$ in fluid inclusions in quartz by removal of $\mathrm{H}_{2} \mathrm{O}$ during crystal-plastic deformation. J Struct Geol 12(7):895-901

Hosieni KR, Howald RA, Scanlon MW (1985) Thermodynamics of the lambda transition and the equation of state of quartz. Am Mineral 70:782-793

Johnson EL, Hollister LS (1995) Syndeformational fluid trapping in quartz: determining the pressure-temperature conditions of deformation from fluid inclusions and the formation of pure $\mathrm{CO}_{2}$ fluid inclusions during grain-boundary migration. $\mathrm{J}$ Metamorph Geol 13:239-249 
Klemd R, Oberthür T, Ouedraogo A (1997) Gold-telluride mineralisation in the Birimian at Diabatou, Burkina Faso: the role of $\mathrm{CO}_{2}-\mathrm{N}_{2}$ fluids. J Afr Earth Sci 35:199-211

Kronenberg AK (1994) Hydrogen speciation and chemical weakening of quartz. Rev Mineral Geochem 29(1):123-176

Kronenberg AK, Kirsby SH, Aines RD, Rossman GR (1986) Solubility and diffusional uptake of hydrogen in quartz at high water pressures: implications for hydrolytic weakening. J Geophys Res 91:12723-12744

Krüger Y, Diamond LW (2001) $P-V-T-X$ properties of two $\mathrm{H}_{2} \mathrm{O}-$ $\mathrm{CO}_{2}-\mathrm{NaCl}$ mixtures up to $850^{\circ} \mathrm{C}$ and $500 \mathrm{MPa}$ : results of a synthetic fluid inclusion study. ECROFI-XVI (Porto, Portugal) Abstracts volume 241-243

Küster M, Stöckhert B (1997) Density changes of fluid inclusions in high-pressure low-temperature metamorphic rocks from Crete: a thermobarometric approach based on the creep strength of the host minerals. Lithos 41:151-167

Lamb WM, Moecher DP (1992) $\mathrm{CO}_{2}$-rich fluid inclusions in the Whitestone Anorthosite: retrograde formation and subsequent modification. J Metamorph Geol 10:763-776

Mavrogenes JA, Bodnar RJ (1994) Hydrogen movement into and out of fluid inclusions in quartz-experimental evidence and geologic implications. Geochim Cosmochim Acta 58:141148

McLaren AC, Cook RF, Hyde ST, Tobin RC (1983) The mechanisms of the formation and growth of water bubbles and associated dislocation loops in synthetic quartz. Phys Chem Min 9:79-94

McLaren AC, Fitzgerald JD, Gerretsen J (1989) Dislocation nucleation and multiplication in synthetic quartz: relevance to water weakening. Phys Chem Min 16:465-482

Morgan GB, Chou IM, Pasteris JD, Olsen SN (1993) Re-equilibration of $\mathrm{CO}_{2}$ fluid inclusions at controlled hydrogen fugacities. J Metamorph Geol 11:155-164
Peng DY, Robinson DB (1976) A new two-constant equation of state. Ind Eng Chem Fundam 15(1):59-64

Ridley J, Hagemann SG (1999) Interpretation of post-entrapment fluid-inclusion re-equilibration at the Three Mile Hill, Marvel Loch and Griffins find high-temperature lode-gold deposits, Yilgarn Craton, Western Australia. Chem Geol 154:257-278

Schmidt Mumm A, Oberthür T, Vetter U, Blenkinsop TG (1997) High $\mathrm{CO}_{2}$ content of fluid inclusions in gold mineralisations in the Ashanti Belt, Ghana: a new category of ore forming fluids? Min Depos 32:107-118

Schmidt C, Bruhn D, Wirth R (2003) Experimental evidence of transformation plasticity in silicates: minimum of creep strength in quartz. Earth Planet Sci Lett 205:273-280

Schwartz MD, Oberthür T, Amanor J, Gyapong W (1992) Fluid inclusion re-equilibration and $P-T-X$ constraints on fluid evolution in the Ashanti gold deposit. Eur J Min 4:1017-1033

Sterner SM, Bodnar RJ (1989) Synthetic fluid inclusions-VII. Reequilibration of fluid inclusions in quartz during laboratorysimulated metamorphic burial and uplift. J Metamorph Geol $7: 243-260$

Sterner SM, Hall DL, Keppler H (1995) Compositional re-equilibration of fluid inclusions in quartz. Contrib Mineral Petrol 119:1-15

Tarantola A, Diamond LW, Stünitz H (2010) Modification of fluid inclusions in quartz by deviatoric stress. I: experimentally induced changes in inclusion shapes and microstructures. Contrib Mineral Petrol. doi:10.1007/s00410-010-0509-z

Vityk MO, Bodnar RJ, Doukhan J-C (2000) Synthetic fluid inclusions: XV. TEM investigation of plastic flow associated with reequilibration of synthetic fluid inclusions in natural quartz. Contrib Mineral Petrol 139:285-297 